Research Paper

\title{
Antimitotic activity of DY131 and the estrogen-related receptor beta 2 (ERRß2) splice variant in breast cancer
}

\author{
Mary M. Heckler ${ }^{1}$, Tizita Zewde Zeleke $^{1}$, Shailaja D. Divekar ${ }^{1}$, Aileen I. Fernandez ${ }^{1}$, \\ Deanna M. Tiek ${ }^{1}$, Jordan Woodrick ${ }^{1}$, Alexander Farzanegan ${ }^{1}$, Rabindra Roy ${ }^{1}$, \\ Aykut Üren $^{1}$, Susette C. Mueller ${ }^{1}$, Rebecca B. Riggins ${ }^{1}$ \\ ${ }^{1}$ Department of Oncology, Lombardi Comprehensive Cancer Center, Georgetown University Medical Center, Washington, DC
20057, USA \\ Correspondence to: Rebecca B. Riggins, email: rbr7@georgetown.edu \\ Keywords: ESRRB, ERRbeta, cell death, mitosis, p38 MAPK
}

Received: August 17, $2015 \quad$ Accepted: May 19, $2016 \quad$ Published: May 30, 2016

\section{ABSTRACT}

Breast cancer remains a leading cause of cancer-related death in women, and triple negative breast cancer (TNBC) lacks clinically actionable therapeutic targets. Death in mitosis is a tumor suppressive mechanism that occurs in cancer cells experiencing a defective $M$ phase. The orphan estrogen-related receptor beta (ERR $\beta$ ) is a key reprogramming factor in murine embryonic and induced pluripotent stem cells. In primates, ERR $\beta$ is alternatively spliced to produce several receptor isoforms. In cellular models of glioblastoma, short form (ERRßsf) and beta2 (ERRß2) splice variants differentially regulate cell cycle progression in response to the synthetic agonist DY131, with ERRß2 driving arrest in G2/M.

The goals of the present study are to determine the cellular function(s) of ligandactivated ERR $\beta$ splice variants in breast cancer and evaluate the potential of DY131 to serve as an antimitotic agent, particularly in TNBC. DY131 inhibits growth in a diverse panel of breast cancer cell lines, causing cell death that involves the p38 stress kinase pathway and a bimodal cell cycle arrest. ERRß2 facilitates the block in G2/M, and DY131 delays progression from prophase to anaphase. Finally, ERRß2 localizes to centrosomes and DY131 causes mitotic spindle defects. Targeting ERRß2 may therefore be a promising therapeutic strategy in breast cancer.

\section{INTRODUCTION}

Breast cancer remains a leading cause of cancerrelated death in women $[1,2]$. The prognosis for patients with hormone receptor-positive and/or human epidermal growth factor receptor 2 (HER2)-positive disease has been significantly improved by antiestrogen and/or anti-HER2 therapies. By contrast, triple negative breast cancer (TNBC), which lacks hormone receptors and HER2, accounts for $13 \%$ of all breast cancers. TNBC is most prevalent in racial and ethnic minority women [3] and lacks clinically actionable therapeutic targets [4].

Mitotic catastrophe, or death in mitosis (DiM), is a tumor suppressive mechanism that occurs in cancer cells experiencing a defective $\mathrm{M}$ phase, ultimately leading to apoptosis or other forms of cell death $[5,6]$. DiM is associated with a number of established cytotoxic chemotherapies and emerging targeted agents such as microtubule targeting drugs (vinca alkaloids and taxanes), inhibitors of mitotic entry and checkpoint kinases, and inhibitors of the multi-protein anaphase promoting complex/cyclosome (APC/C) or the spindle assembly checkpoint (SAC) [7]. However, there are significant liabilities inherent to some of these existing approaches, particularly those targeting microtubules because they are essential for cytoskeletal structure and vesicle trafficking outside of mitosis. An incomplete mitotic block allows slippage into the next G1 phase where, in the presence of apoptotic defects that may prevent elimination of these cells, chromosomal instability can lead to more aggressive tumor behavior. Other approaches include the inhibition of centrosome clustering, a mechanism to complete bipolar division used by cancer cells with centrosomal amplification; small molecules which inhibit this process are being 
developed as novel antimitotic therapies in breast and other cancers [8-11]. MYC-mediated modulation of pro-apoptotic $\mathrm{BH} 3$-only proteins has also recently been implicated in the control of DiM [12].

An attractive approach to inducing DiM that may avoid some pitfalls of microtubule inhibitors could be to inhibit a target protein that is enriched in cancer vs. normal cells and has pro-tumorigenic roles in both mitosis and interphase (e.g. survivin/BIRC5) [7]. Activation of a tumor suppressor pathway with mitotic and nonmitotic functions would be similarly beneficial. Nuclear receptors have historically been very successful targets for drug development. Estrogen-related receptors (ERRs) are orphan members of this protein family that have no known endogenous ligands, although their function can be modified by synthetic ligands [13-15] and the abundance of binding partners [16-19]. In mice, ERR $\beta$ (ESRRB/ERR2/ERRbeta/ESRL2/NR3B2) has emerged as a key reprogramming factor in embryonic and induced pluripotent stem cells [20-22], where it promotes a more permissive G1/S checkpoint [23, 24]. By contrast, exogenous expression of human ERR $\beta$ has tumor suppressive activities that activate the G1/S checkpoint through the induction of CDKN1A (p21) in prostate cancer cells [25]. The discrepancy in mouse vs. human function of ERR $\beta$ may be explained, in part, by alternative splicing [26]. Lower organisms express only the short form of ERR $\beta$, a transcriptionally active nuclear receptor of 433 amino acids hereafter referred to as ERR $\beta$ sf. In primates, however, the ESRRB locus contains three additional exons and gives rise to two other known transcripts with alternative carboxyl-terminal extensions: ERRbeta2 (ERR $\beta 2,500$ amino acids) and ERR $\beta-\Delta 10$ (508 amino acids) [26]. We have recently demonstrated that in cellular models of glioblastoma (GBM), the ERR $\beta$ sf and ERR $\beta 2$ splice variants differentially regulate cell cycle progression in response to a synthetic ERR agonist, DY131 [27, 28]. As in prostate cancer [25], DY131stimulated ERR $\beta$ sf mediates a G1 arrest concurrent with the induction of $\mathrm{p} 21$. However, activation of ERR $\beta 2$ by this ligand drives arrest in G2/M [27].

The goals of the present study are to determine the cellular function(s) of ligand-activated ERR $\beta$ splice variants in breast cancer and evaluate the potential of DY131 to serve as an antimitotic agent, particularly in TNBC. DY131 inhibits growth in a diverse panel of breast cancer cell lines, causing cell death that involves the p38 stress kinase pathway and a bimodal cell cycle arrest. ERR $\beta 2$ facilitates the block in $G 2 / M$, and DY131 delays progression from prophase to anaphase. Finally, ERR $\beta 2$ is a cytosolic protein that also localizes to centrosomes, and DY131 treatment leads to the appearance of multi- and monopolar spindles. Activation of ERR $\beta$, particularly the ERR $\beta 2$ splice variant, may therefore be a promising therapeutic strategy in breast cancer.

\section{RESULTS}

\section{ERRß2 has no transcription factor activity in breast cancer cells}

The estrogen-related receptor (ERR) family has direct, DNA binding-associated transcriptional activity at a number of promoter elements, including the estrogenrelated response element (ERRE) half site, classical estrogen response elements (EREs), and a hybrid ERE/ ERRE element [29-32]. These receptors have also been implicated in indirect transcriptional control through tethering to AP1 [33] and SP1 [34] transcription factors. We recently published that ERR $\beta$ sf has constitutive and ligand-modulated activity on the p 21 promoter in cellular models of glioblastoma (GBM, [27]) but that ERR $\beta 2$ cannot activate the $\mathrm{p} 21$ promoter-reporter. Here, we measured the activity of these exogenous splice variants on ERE- and ERRE-luciferase heterologous promoter-reporter constructs in breast cancer cells. In estrogen receptor alpha-negative (ER-) MDA-MB-231 cells, exogenous ERR $\beta$ sf has robust basal transcriptional activity that is equally enhanced by exposure to two ERRß/ $\gamma$ synthetic agonists: DY131 (DY) or GSK4716 (GSK, Figure 1A). ERR $\gamma$ is also active under basal and ligand-stimulated conditions, but ERR $\beta 2$ has no effect on ERE-luciferase expression. In estrogen receptor alphapositive (ER+) MCF7 cells, a similar trend is observed for ERRE-luciferase; ERR $\beta$ sf and ERR $\gamma$ both show basal and ligand-induced transcriptional activity in response to DY131, while ERR 32 does not (Figure 1B). We showed previously that ERR $\beta 2$ is a dose-dependent dominantnegative inhibitor of ERR $\beta$ sf on the p21 promoter in GBM cell lines [27]. Here, ERR $\beta 2$ behaves similarly on the ERRE-luciferase construct in MCF7 breast cancer cells (Figure 1C), where its exogenous expression also significantly represses background ERRE activity.

Several molecular mechanisms could explain ERR $\beta 2$ 's dominant-inhibitory activity. Ligand-regulated and orphan nuclear receptors both rely heavily on partner proteins - coactivators and corepressors - to confer specificity upon their transcriptional activity [35]. While most studies of ERR coactivators have focused on PGC1 $\alpha$ and $\beta$ (e.g. [17]), ERR $\beta$ sf requires nuclear receptor coactivator 3 (NCOA3 or AIB1) to perform transcriptiondependent functions in mouse embryonic stem cell selfrenewal [21], and cooperates with AIB1 to modulate G1/S checkpoint integrity in this context $[23,24]$. Here, we show that exogenous expression of AIB1 [36] alone can induce ERRE-luciferase activity in MCF7 cells, and enhance ERR $\beta$ sf-mediated activation of the ERREluciferase reporter in the absence of ligand (Figure 1D). By contrast, ERR $\beta 2$ significantly inhibits AIB1-mediated induction of ERRE-luciferase activity. These data show that the ERR $\beta 2$ splice variant has no transcription factor activity and serves as a dominant-negative inhibitor 
of ERR $\beta$ sf-dependent transcription in breast cancer. They further suggest that this is due, at least in part, to competition for coactivators.

\section{$E R R \beta / \gamma$ agonist DY131 is growth-inhibitory in breast cancer cells}

The role of ERR $\beta$ and its splice variants in breast cancer is not fully defined. High levels of total ESRRB mRNA in primary breast tumors are associated with a reduction in cells in $\mathrm{S}$ phase and increased expression of estrogen receptor beta $(\mathrm{ER} \beta)$ [37]. In exogenous expression studies, ERR $\beta$ sf interacts with $\mathrm{ER}$, alters the intranuclear localization of ER, and suppresses ER-mediated gene transcription in MCF7 cells [38]. Exogenous expression of ERR $\beta$ "long form" (a synonym for ERR $\beta 2$ used by some) in MCF7 cells leads to apoptosis and also shows an interaction with ER that is attenuated upon exposure to estradiol [39]. ERR $\gamma$ 's role in breast cancer is complex and contextdependent; while several studies show an association between this receptor and indicators of good prognosis [37] or directly demonstrate a growth-suppressive role $[40,41]$, others report that it can promote estrogenindependent and Tamoxifen-resistant growth [4246], and metabolically reprogram non-transformed mammary epithelial cells to successfully adapt to anoikis [47].
A.

MDA-MB-231, ERE-luciferase activity

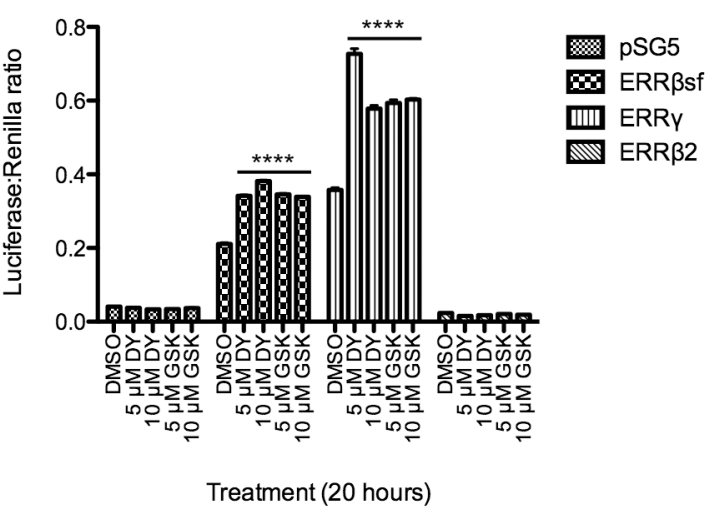

C.

MCF7, ERRE-luciferase

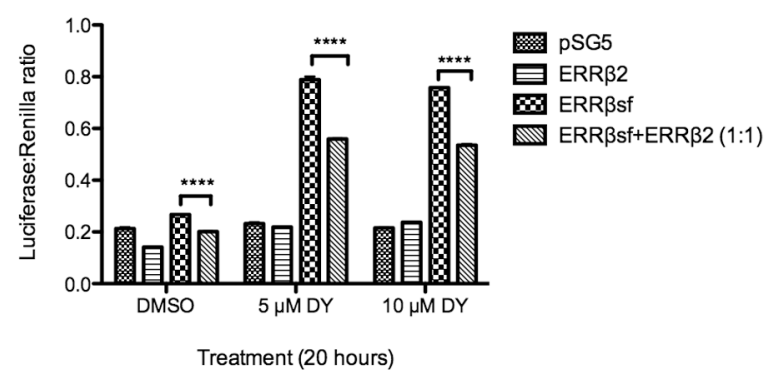

B.
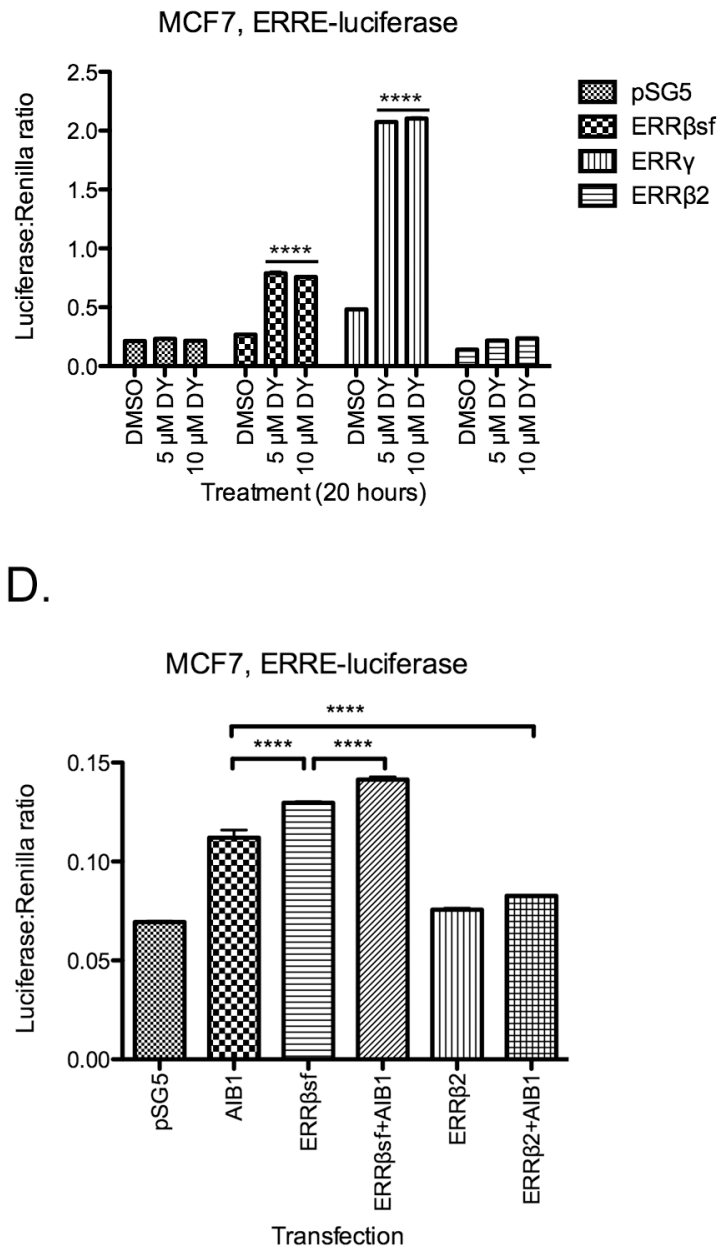

Figure 1: ERRß2 has no transcription factor activity in breast cancer cells. MDA-MB-231 A. and MCF7 cells B. transiently co-transfected with the indicated promoter-reporter luciferase constructs and receptor cDNA, then treated with either DY131 (DY), GSK4716 (GSK), or DMSO control (18-20 h) as shown. N = 3 for a representative assay peformed in triplicate, two-way ANOVA with Bonferroni post-test. **** denote post-hoc Bonferroni comparison for each drug treatment vs. DMSO control. C, MCF7 cells transiently co-transfected with ERRE-luciferase and ERR $\beta 2$, ERR $\beta$ sf, or a 1:1 ratio of the two cDNAs, then treated with DY131 or DMSO control for $18-20 \mathrm{~h} . \mathrm{N}=3$ for a representative assay performed in triplicate, two-way ANOVA with Bonferroni post-test. D, MCF7 cells transiently co-transfected with ERRE-luciferase and AIB1, ERR $\beta$ sf, ERR $\beta 2$, or a 1:1 ratio of AIB1:ERR $\beta$ sf or AIB1:ERR $\beta 2$ for $\sim 24 \mathrm{~h}$. $\mathrm{N}=3$ for a representative assay shown in triplicate, two-way ANOVA with Bonferroni post-test. 
We therefore tested the capacity of the ERR $\beta / \gamma$ agonist DY131 to modulate breast cancer and nontransformed mammary epithelial cell growth, as measured by crystal violet staining (Figure 2A, Supplementary Figure S1A). In addition to ER+ MCF7 cells and ERMDA-MB-231 cells representative of the mesenchymal stem-like subtype of triple negative breast cancer (TNBC) [48], we used two additional TNBC cell lines - HCC1806 (basal-like 2) and MDA-MB-468 (basallike 1) - in addition to the MCF10A non-transformed mammary epithelial cell line. All cancer cell lines are completely growth-inhibited by the highest concentration $(10 \mu \mathrm{M})$ of DY131, while MCF7, MDA-MB-231, and MDA-MB-468 are also significantly inhibited by $5 \mu \mathrm{M}$, and MCF7 and MDA-MB-468 cells by $2.5 \mu \mathrm{M}$. MCF $10 A$ cells are only modestly growth-inhibited by 10 $\mu \mathrm{M}$ DY131, and responsiveness is not fully explained by differences in the basal (untreated) growth rate of the cell lines (Supplementary Figure S1B), suggesting that DY131 preferentially inhibits the growth of cancer cells. In clonogenic survival assays, MDA-MB-231 show a dose-dependent reduction in colony formation after a single, $24 \mathrm{~h}$ exposure to DY131 (Figure 2B), while MCF7 cells show reduced colony formation at $10 \mu \mathrm{M}$. We then measured expression of two endogenous ERR $\beta$ splice variants - ERR $\beta$ sf and ERR $\beta 2$ - in these cell lines (Figure 2C) using a pair of monoclonal antibodies that preferentially detect each endogenous splice variant [27]. Both antibodies detect exogenous/overexpressed receptor, as demonstrated by the positive controls (cells transfected with the indicated cDNA). ERR $\beta 2$ and ERR $\beta$ sf are expressed in all cell lines. We previously reported [42] that MCF7 cells express very low to undetectable levels of ERR $\gamma$. We confirm this finding here, and show that this is also true for MDA-MB-231 and MDA-MB468 cells, while MCF10A and HCC1806 cells express some ERR $\gamma$ (Figure 2D). In summary, multiple breast cancer cell lines are preferentially growth-inhibited by the ERR $\beta / \gamma$ agonist DY131 as compared to a non-transformed breast epithelial cell line, and all express detectable levels of ERR $\beta$ sf and ERR $\beta 2$ protein, whereas ERR $\gamma$ protein expression is not consistently observed.

\section{DY131 induces apoptotic cell death}

To determine whether the growth-inhibitory activity of DY131 can be attributed to cytotoxic (cell killing) activity, all 5 cell lines were treated with increasing concentrations of DY131 and analyzed for fragmented (subG1) DNA content as a measure of cell death (Figure 3A). All breast cancer cell lines show a significant, dose-dependent increase in the subG1 fraction, with MDA-MB-231 and MDA-MB-468 cells being the most sensitive, whereas non-transformed MCF10A cells are

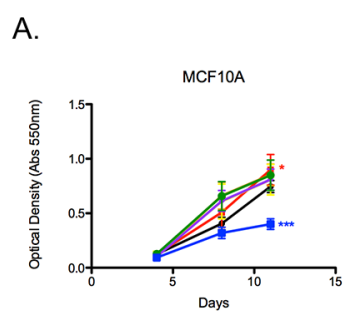

B.

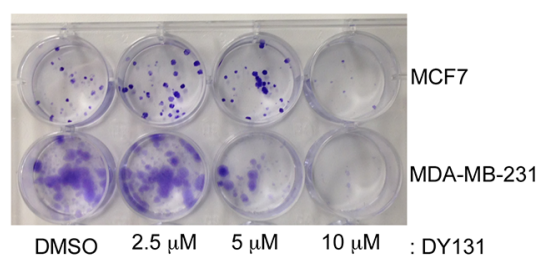

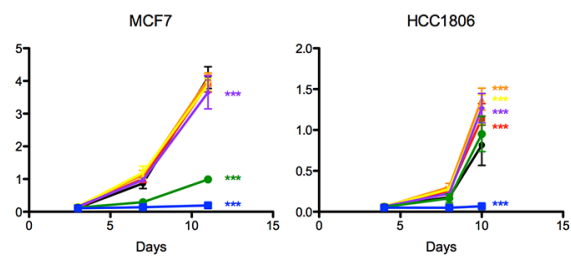

C.
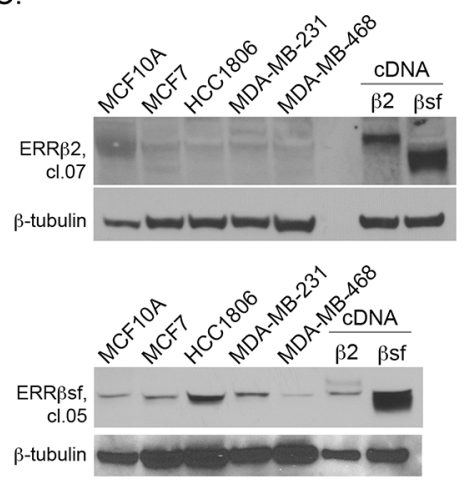
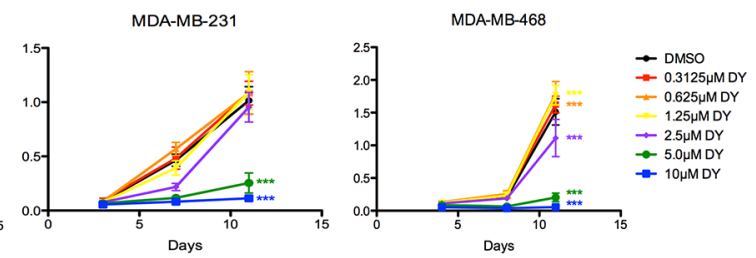

D.

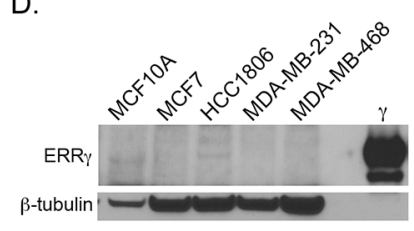

Figure 2: ERRß/ $\gamma$ agonist DY131 is growth-inhibitory in breast cancer cells. A. Crystal violet staining of breast cancer and non-transformed breast epithelial cell lines in the presence or absence of the indicated concentrations of DY131 or DMSO control over time. $\mathrm{N}=6$ for a representative assay performed in sextuplicate, two-way ANOVA with Bonferroni post-tests in each cell line vs. DMSO control at Day 10/11. B. Clonogenic survival assay for MCF7 and MDA-MB-231 cells seeded at low density and cultured for $13 \mathrm{~d}$ after a single, $24 \mathrm{~h}$ exposure to the indicated concentrations of DY131. C-D. Representative Western blot analysis of basal ERR $\beta$ sf, ERR $\beta 2$, and ERR $\gamma$ expression in non-transformed mammary epithelial and breast cancer cells. $\beta 2$ and $\beta$ sf positive controls are from MDA-MB-231 cells transiently transfected with the indicated cDNA. $\gamma$ positive control is purified protein. 
unaffected by DY131 treatment. DY131 has been reported to have off-target activity through direct inhibition of Hedgehog signaling by binding to Smoothened via the same mechanism as more conventional inhibitors (cyclopamine and vismodegib, [49]), and in prostate cancer cells exogenous ERR $\beta$ sf can regulate Hedgehog target genes [50]. However, it is well-established that non-transformed MCF10A, MCF7, and MDA-MB-231 cells lack expression of Smoothened and are relatively resistant to cell killing by Smoothened inhibitors [51-53]. Consistent with this, neither cyclopamine nor vismodegib phenocopies DY131-induced cell death in MDA-MB-231 cells (Figure 3B). Smoothened-independent mechanisms of Hedgehog pathway signaling can include activation of the transcription factor GLI Family Zinc Finger 1 (GLI1) [54], so we tested whether DY131 could inhibit GLI1 transcription factor activity in MDA-MB-231 cells (Supplementary Figure S2). Exogenous GLI1 activity is modestly inhibited by DY131, though not to the same extent as by the direct GLI inhibitor arsenic trioxide (ATO [54]). Therefore, DY131 may have Hedgehog pathwayinhibitory activities in some cellular contexts, but our data suggest that this mechanism of action is not a key contributor to DY131-induced cell death in breast cancer cell lines.

To better define the cellular mechanism of death induced by DY131, we stained live cells for Annexin $\mathrm{V}$ surface expression and propidium iodide uptake
(Figure 3C-3E). There is a significant, three to fourfold increase in Annexin V single-positive cells upon DY131 treatment in MDA-MB-231 and MDA-MB-468 cells, indicative of early-stage apoptosis. MCF7 cells show no early apoptosis, while HCC1806 cells show a small, statistically significant increase in early apoptosis. HCC1806 cells exhibit significantly increased doublepositive and propidium iodide single-positive staining associated with late-stage apoptosis and necrosis, respectively. MCF7 cells show a modest (though statistically significant) increase in propidium iodide single-positive cells in the presence of $10 \mu \mathrm{M}$ DY131. By contrast, DY131 does not induce any stage of apoptosis in MCF10A cells.

In our prior study of cellular models of GBM, we showed that DY131-induced apoptosis is accompanied by cleavage of poly ADP-ribose polymerase (PARP) [27], a well-characterized substrate of executioner caspases [5]. MCF7, MDA-MB-231, and MDA-MB-468 cells exhibit PARP cleavage in response to DY131 (Figure 3F), while HCC1806 and MCF10A cells do not. All cells display PARP cleavage upon treatment with the doxorubicin positive control. We also observe an increase in Ser139 phosphorylation of histone $\mathrm{H} 2 \mathrm{AX}(\gamma \mathrm{H} 2 \mathrm{AX})$, a histone modification that can accompany DNA damage, apoptosis, $\mathrm{X}$ chromosome inactivation, and/or mitosis (reviewed in $[55,56])$ in the four breast cancer cell lines, but not MCF10A cells.
A
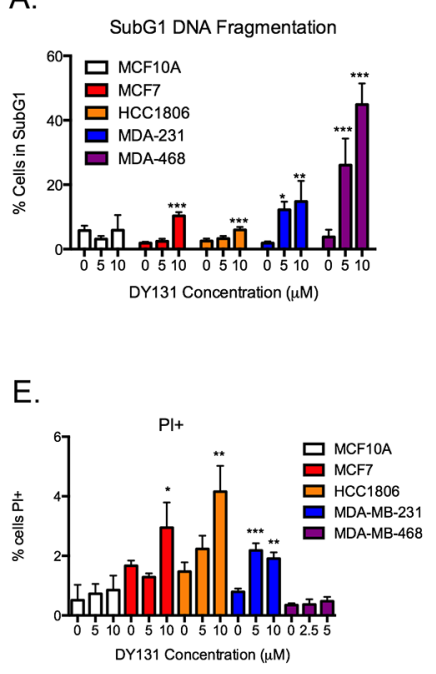

B.

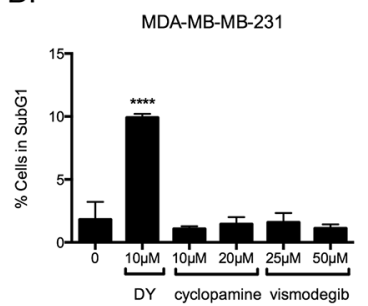

C.

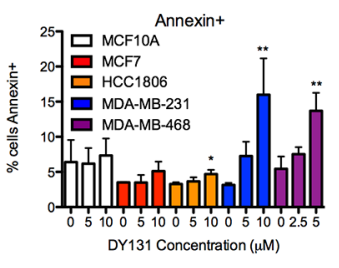

D.

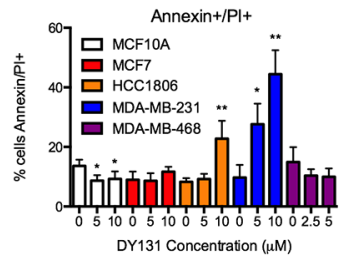

F.

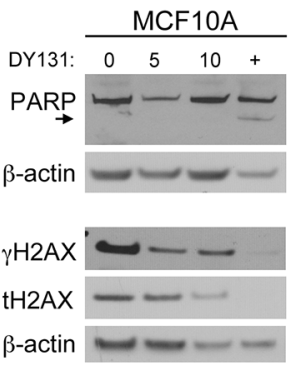

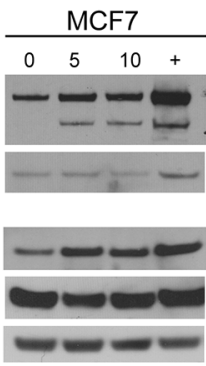

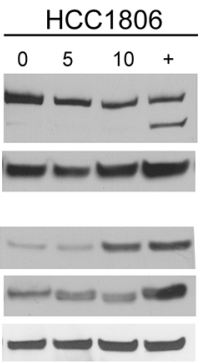

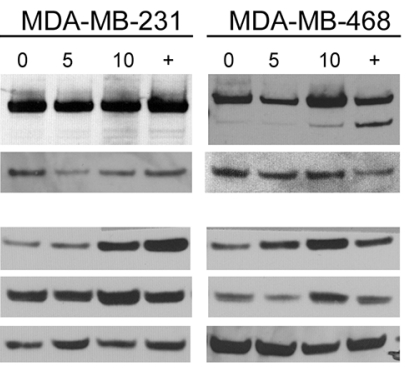

Figure 3: DY131 induces apoptotic cell death. A. Percent of cells exhibiting fragmented DNA (subG1 DNA content as measured by propidium iodide staining of fixed cells) after exposure to DY131 for $24 \mathrm{~h}$ as determined by flow cytometry. $\mathrm{N}=3-5$ independent assays, one-way ANOVA with Tukey's post-test. B. Effect of Smoothened inhibitors cyclopamine and vismodegib on subG1 DNA content in MDA-MB-231 cells after $24 \mathrm{~h}$ exposure. $\mathrm{N}=3$ independent assays, one-way ANOVA with Tukey's post-test. C-E. Percent of cells staining positive for cell-surface Annexin V and/or propidium iodide uptake by live cells after exposure to DY131 for 12-24 h as determined by flow cytometry. $\mathrm{N}=3-5$ independent assays, one-way ANOVA with Tukey's post-test. F. Representative Western blot analysis of PARP, $\gamma \mathrm{H} 2 \mathrm{AX}$, and total H2AX in DY131-treated cells $(24 \mathrm{~h}) .+$ denotes doxorubicin positive control (24 h). Arrowhead indicates PARP cleavage product. 


\section{DY131 does not induce a conventional DNA damage response or bind DNA directly}

The induction of $\gamma \mathrm{H} 2 \mathrm{AX}$ by DY131 raises the possibility that this compound can elicit a DNA damage response (DDR). In the context of the DDR, rapid H2AX phosphorylation is catalyzed by ataxia telangiectasia mutated (ATM) or ataxia telangiectasia and Rad3-related (ATR) at double-strand breaks (DSBs). However, a DY131 time course in MCF7 and MDA-MB-231 cells shows no activation of this signaling cascade in contrast to the doxorubicin positive control, and the induction of $\gamma \mathrm{H} 2 \mathrm{AX}$ is not detected until later time points $(\geq 20 \mathrm{~h}$, Figure 4A). Furthermore, pre-treatment with the ATM inhibitor KU-55933 does not prevent DY131-induced $\gamma \mathrm{H} 2 \mathrm{AX}$ (Figure 4B). We subsequently performed a surface plasmon resonance (BIAcore) experiment with DY131 and the related ERR agonist GSK4716 to determine whether these compounds could bind double strand (ds) or single strand (ss) DNA directly (Figure 4C-4E). While the mitoxantrone positive control readily binds dsDNA and ssDNA, neither ERR agonist is competent to do so. Altogether, these data support the conclusion that DY131induced $\gamma \mathrm{H} 2 \mathrm{AX}$ is not associated with direct DNA damage or nucleic acid binding.

\section{DY131 induces G1 and G2/M cell cycle arrest}

Prior studies by our group [27] and others [25, 57] have shown that ERR $\beta$ sf or ERR $\gamma$ can induce G1 cell cycle arrest, while ERR $\beta 2$ mediates a $\mathrm{G} 2 / \mathrm{M}$ arrest in response to DY131 [27]. Here, we show that MCF7, HCC1806, and MDA-MB-468 undergo a significant G1 arrest at $5 \mu \mathrm{M}$ (Figure 5A), while MDA-MB-468 cells show minimal arrest and MDA-MB-231 cells show none. There is a dose-dependent trend towards G1 arrest in MCF10A cells, but this is not statistically significant. All cell lines show a significant reduction in $\mathrm{S}$ phase fraction (Figure 5B), with MCF10A cells again the least affected. The magnitude of G1 arrest is reflected in a corresponding increase in p21 expression (Figure 5C), which is not p53-dependent since MDA-MB-468 cells have mutated p53 and HCC1806 cells
A.

MCF7

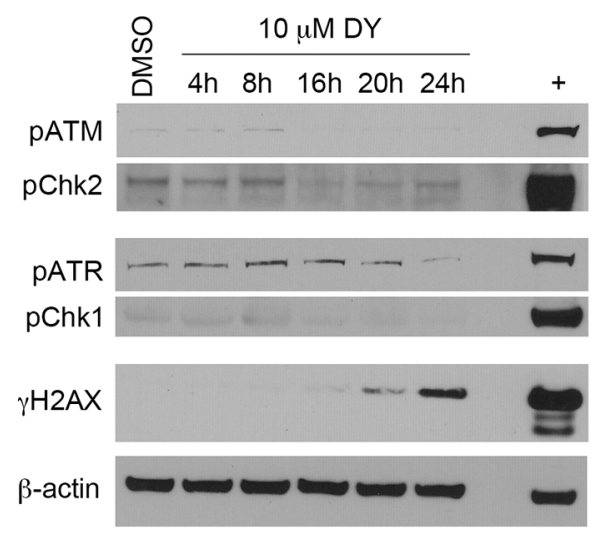

C.

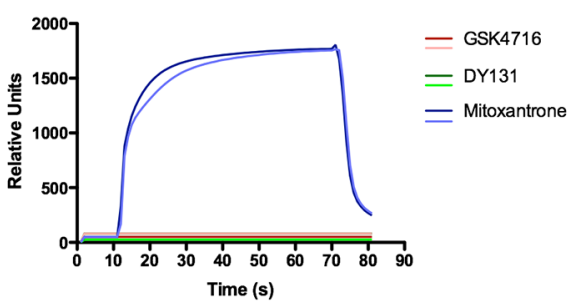

MDA-MB-231

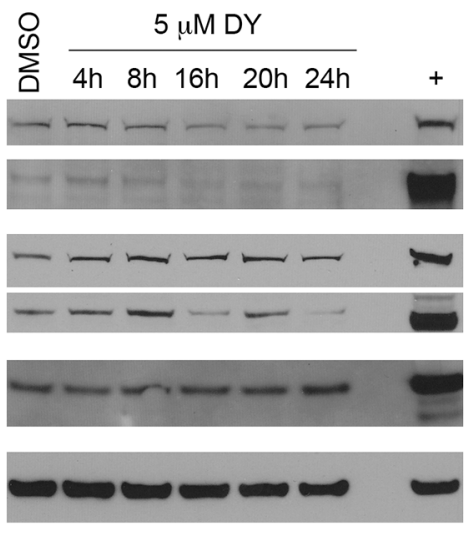

D.

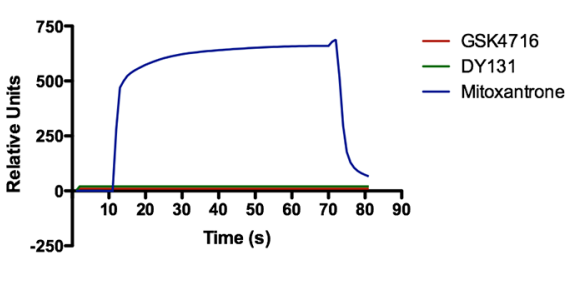

E.
B.

MDA-MB-231

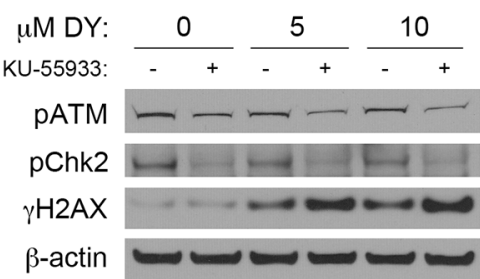

\begin{tabular}{|c|c|c|}
\hline Compound & $\begin{array}{c}\text { dsDNA } \\
(\text { RU) }\end{array}$ & $\begin{array}{c}\text { ssDNA } \\
\text { (RU) }\end{array}$ \\
\hline GSK4716 & ND $^{1}$ & ND \\
\hline DY131 & ND & ND \\
\hline Mitoxantrone & 1767 & 659 \\
\hline
\end{tabular}

$\mathrm{ND}=$ not detectable

Figure 4: DY131 does not induce a conventional DNA damage response or bind DNA directly. A. Representative time course Western blot analysis of DNA damage response kinases and $\gamma \mathrm{H} 2 \mathrm{AX}$ in response to DY131 in MCF7 and MDA-MB-231 cells. + denotes doxorubicin positive control $(24 \mathrm{~h})$. B. Representative Western blot analysis of ATM signaling pathway activation and $\gamma \mathrm{H} 2 \mathrm{AX}$ in MDA-MB-231 cells in response to DY131 following a $1 \mathrm{~h}$ pre-treatment with ATM inhibitor KU-55933. C-D. Surface plasmon resonance (BIAcore) sensogram of DY131, GSK4716, or mitoxantrone positive control binding to dsDNA or ssDNA. E. Table summarizing results of BIAcore binding studies. Values shown are the peak Relative Unit (RU) values after $60 \mathrm{~s}$ injection of compound. ND ${ }^{1}=$ not detectable. Data shown are from a representative experiment, performed twice. 
are p53 null [58]. Neither Smoothened inhibitor causes G1 arrest or a reduction in $\mathrm{S}$ phase in MDA-MB-231 cells (Figure 5D).

The four breast cancer cell lines all exhibit significant G2/M arrest in the presence of $10 \mu \mathrm{M}$ DY131, with MDA-MB-231 cells also showing a significant, dosedependent G2/M arrest at $5 \mu \mathrm{M}$ (Figure 5E). Consistent with this, in all breast cancer cell lines we observe a strong increase in Ser10 phosphorylation of histone H3 (Figure $5 \mathrm{~F}$ ), a histone modification associated with chromatin condensation in prophase [59-61], as well as immediate early gene transcription [62]. Neither a G2/M arrest nor a robust increase in Ser10 phosphorylation of histone $\mathrm{H} 3$ occurs in non-transformed MCF10A cells treat at the same concentrations of DY131. In summary, DY131 induces a bimodal cell cycle arrest in MCF7, HCC1806, and (to some extent) MDA-MB-468 cells, but only G2/M arrest in MDA-MB-231 cells.

\section{DY131-induced p38 MAPK activity is required for cell death, but not cell cycle arrest}

One potential explanation for DY131-induced changes in $\mathrm{H} 3$ Ser10 phosphorylation and/or $\gamma \mathrm{H} 2 \mathrm{AX}$ in the absence of a conventional DDR is activation of the p38 mitogen-activated protein kinase (MAPK) cascade. $\mathrm{p} 38$ can directly phosphorylate $\mathrm{H} 2 \mathrm{AX}$ in vitro [63] and is responsible for apoptosis-associated in vivo $\gamma \mathrm{H} 2 \mathrm{AX}$ induction either directly or through activation of downstream kinases such as mitogen-activated protein kinase activated kinase 2 (MAPKAPK2) [64, 65]. Similarly, p38 can phosphorylate H3 Ser10 directly in vitro [66], as can the p38 substrate mitogen- and stressactivated protein kinase 1 (MSK1) [62].

Activating phosphorylation of p38 is weak or absent in MCF10A and MCF7 cells treated with DY131 (Figure 6A (Western blot) and 6B (densitometry)). By contrast, HCC1806 show a trend towards p38 phosphorylation, while MDA-MB-231 and MDA-MB-468 cells show a significant, two to six-fold induction in p38 phosphorylation at $10 \mu \mathrm{M}$. Because the latter two cell lines are also the most responsive to DY131-induced G2/M arrest and cell death, we pretreated them with the inhibitor SB203580 to test p38's contribution to these phenotypes. Pharmacological p38 inhibition significantly and dose dependently reduces DY131-induced subG1 (cell death) in both cell lines (Figure 6C), but does not inhibit DY131mediated G2/M arrest (Figure 6D). Altogether, these data show that DY131 activates p38 in breast cancer cells, and while this plays a key role in drug-induced cell death, it is not required for $\mathrm{G} 2 / \mathrm{M}$ arrest.

\section{ERRß2 promotes DY131-induced histone $\mathrm{H3}$ phosphorylation}

Because our prior studies in GBM have shown that exogenous ERR $\beta 2$ promotes DY131-mediated $\mathrm{G} 2 / \mathrm{M}$ arrest [27], we tested whether this is also true in
A.

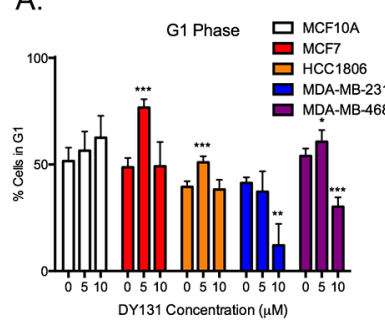

D.

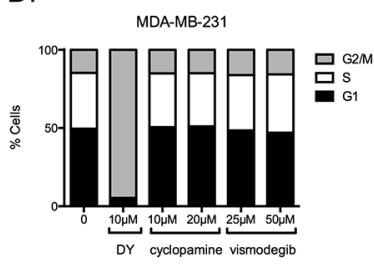

B.

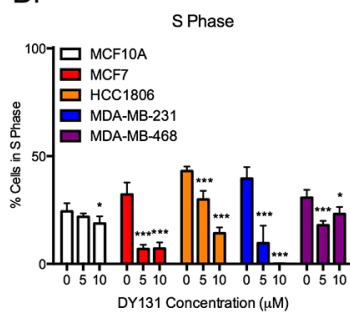

E.

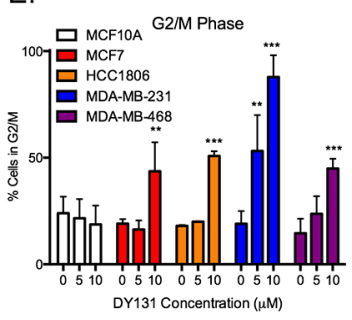

C.

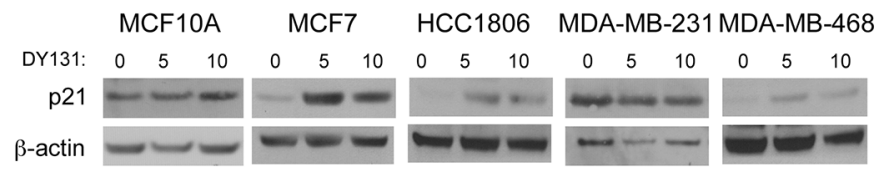

$\mathrm{F}$.

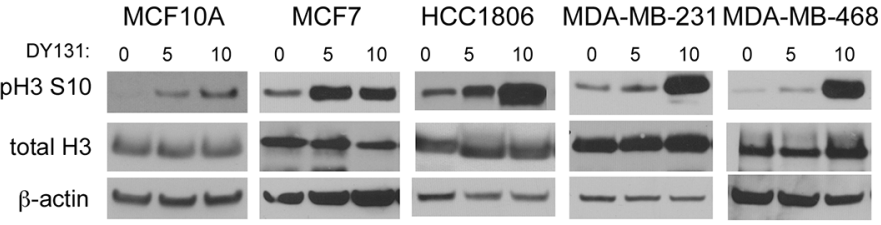

Figure 5: DY131 induces G1 and G2/M cell cycle arrest. A. Percent of cells in the G1 phase of the cell cycle after exposure to DY131 for $24 \mathrm{~h}$ as determined by flow cytometry. $\mathrm{N}=3-5$ independent assays, one-way ANOVA with Tukey's post-test. B. Percent of cells in S phase of cell cycle after exposure to DY131 for $24 \mathrm{~h}$ as determined by flow cytometry. $\mathrm{N}=3-5$ independent assays, one-way ANOVA with Tukey's post-test., C. Representative Western blot analysis of p21 in DY131-treated cells (24 h). D. Effect of Smoothened inhibitors cyclopamine and vismodegib on the cell cycle profile of MDA-MB-231 cells after $24 \mathrm{~h}$ exposure. Data shown are from a representative experiment, performed three times. E. Percent of cells in the G2/M phase of the cell cycle after exposure to DY131 for $24 \mathrm{~h}$ as determined by flow cytometry. $\mathrm{N}=3-5$ independent assays, one-way ANOVA with Tukey's post-test. F. Representative Western blot analysis of phosphorylated Serine 10 and total Histone H3 in DY131-treated cells (24 h). 
breast cancer. We selected the cell line with the strongest DY131-induced G1 arrest at $5 \mu \mathrm{M}$ (MCF7, see Figure $5 \mathrm{~A})$ in which to test whether exogenous ERR $\beta 2$ can induce markers of G2/M arrest. MCF7 cells transiently transfected with exogenous ERR $\beta 2$ (visualized using the cl.05 antibody so as to also show endogenous ERR $\beta$ sf) show a strong increase in Ser10 phosphorylation of histone H3 (Figure 7). We could not determine whether exogenous ERR $\beta 2$ suppresses DY131-mediated G1 arrest as measured by a reduction in $\mathrm{p} 21$, because in these cells transient transfection, even with the empty vector, artificially increases basal p21 levels such that DY131mediated induction is no longer observable (not shown).

\section{DY131 delays chromosome segregation in mitosis}

Our data demonstrating DY131-induced G2/M cell cycle arrest, coupled with DY131-mediated induction of histone H3 Ser10 phosphorylation that is potentiated by exogenous ERR $\beta 2$, are indicative of an early (preanaphase) mitotic defect, but a more precise definition of where DY131 can perturb mitosis is required. We therefore performed live-cell confocal video microscopy of MCF7 cells stably transfected with H2B-GFP [67]; these cells were used for this experiment because although they are aneuploid, most contain a single nucleus, which enables semi-automated tracking of mitotic progression [68]. Cultures were enriched for cells with G2 DNA content by exposure to nocodazole, and then released into media

A.

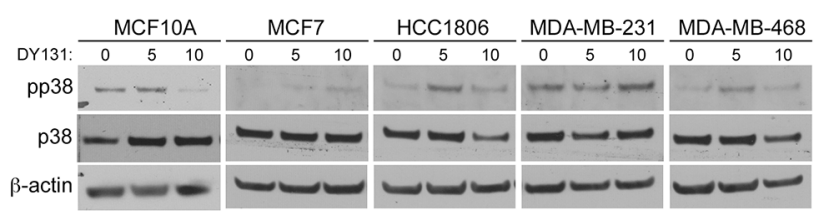

C.
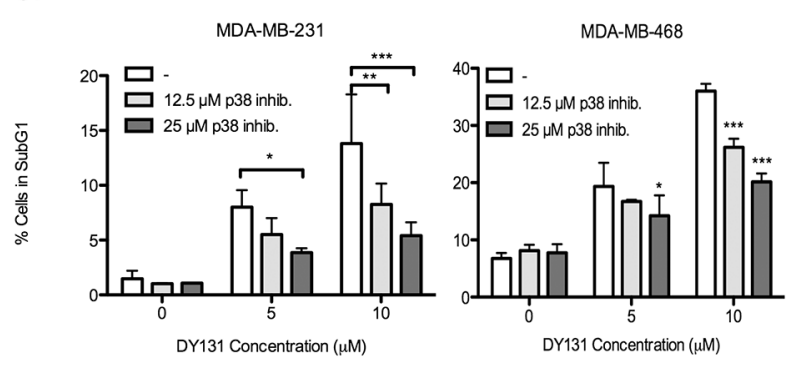

containing DMSO control or DY131 (Figure 8A). As a control, we also tested two different compounds with known effects on mitotic progression. The cyclin-dependent kinase inhibitor flavopiridol accelerates mitotic exit, leading to a pseudo G1-like state with $>4$ n DNA content [69], while the microtubule stabilizer paclitaxel halts cells in prophase [70]. We observe both of these phenotypes in MCF7 cells (Supplementary Movies 1 and 2). Nocodazole-treated cells released into DMSO show typical mitotic transit, with a mean time of progression from prophase to anaphase of $\sim 39$ minutes (Figure 8B, Supplementary Movie S3). By contrast, release into DY131 causes a significant, dose-dependent delay in mitotic progression in those cells that do divide (Supplementary Movies S4 and S5). Thirty-three percent (33\%) of cells in $5 \mu \mathrm{M}$ remain pre-anaphase, while $66 \%$ eventually divide to enter the next G1 phase. Of cells in 10 $\mu \mathrm{M}$ DY131, 35\% do not progress to anaphase, and $65 \%$ eventually divide. DY131-exposed cells also exhibit a more disorganized metaphase plate with evidence of lagging chromosomes (Figure 8A, white arrowheads in metaphase panels from DY131-treated cells). These data suggest that DY131 delays mitotic progression from prophase to anaphase by causing errors in chromosome segregation.

\section{DY131 causes monopolar and multipolar spindles}

Delays in mitotic progression and lagging chromosomes caused by acute exposure to DY131 prompted

B.

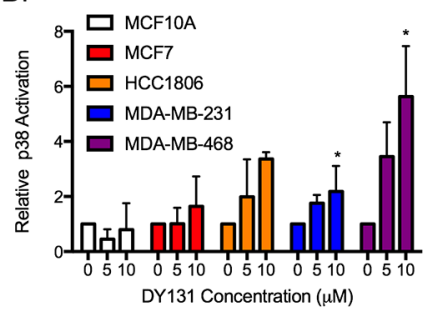

D.

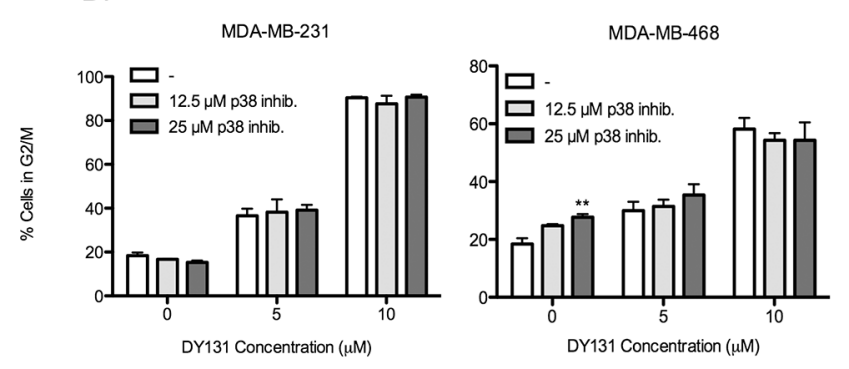

Figure 6: DY131-induced p38 MAPK activity is required for cell death, but not cell cycle arrest. A. Representative Western blots for activating phosphorylation of p38 in DY131-treated cells. B. Densitometry analysis of the ratio of phosphorylated to total p38 relative to $\beta$-actin are normalized to the level of the DMSO control for each cell line. $\mathrm{N}=3$ independent assays, one-way ANOVA with Tukey's post-test. C. Percent of cells exhibiting fragmented DNA (subG1 DNA content as measured by propidium iodide staining of fixed cells) after a $1 \mathrm{~h}$ pre-treatment with p38 inhibitor SB203580 before exposure to DY131 for an additional $24 \mathrm{~h}$ as determined by flow cytometry. $\mathrm{N}=3$ independent assays, two-way ANOVA with Bonferroni post-test. D., Percent of cells in the G2/M phase of the cell cycle after a $1 \mathrm{~h}$ pre-treatment with p38 inhibitor SB203580 before exposure to DY131 for an additional $24 \mathrm{~h}$ as determined by flow cytometry. $\mathrm{N}=3$ independent assays, two-way ANOVA with Bonferroni post-test. 


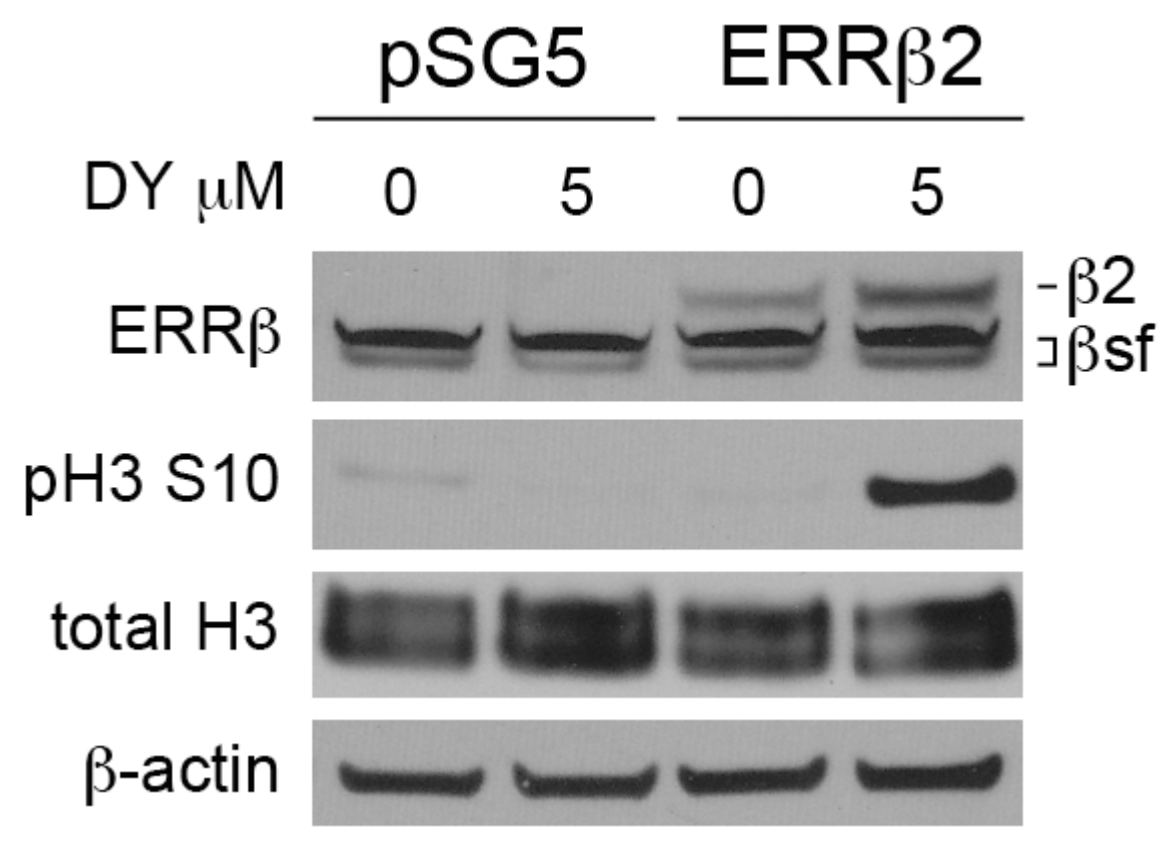

Figure 7: ERRß2 promotes DY131-induced histone H3 phosphorylation. Representative Western blot analysis of ERR $\beta 2$, phosphorylated Serine 10 and total Histone H3 in MCF7 cells transiently transfected with either ERR $\beta 2$ or pSG5 empty vector, then treated with DY131 or DMSO control for 18-20 h. Exogenous ERRß2 expression was detecting using H6705 (cl.05) in order to also visualize endogenous ERRßsf.

A.

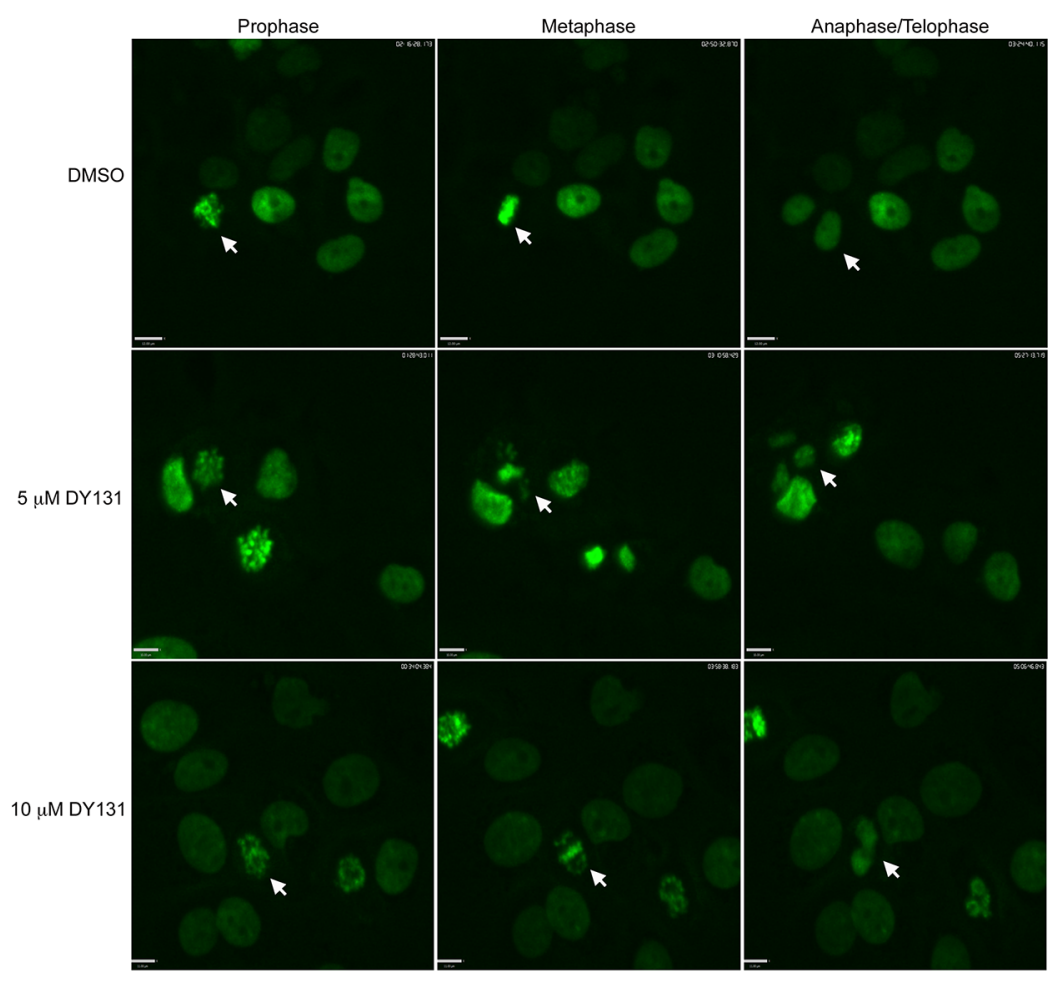

B.

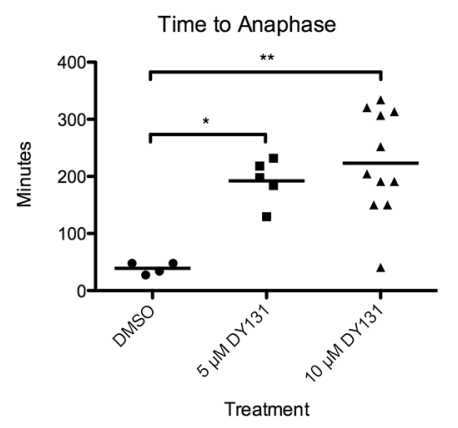

Figure 8: DY131 delays chromosome segregation in mitosis. A. Individual frames representative of prophase, metaphase, and anaphase/telophase from live-cell confocal microscopy of MCF7 cells stably expressing GFP-H2B. Cells were accumulated in G2 by exposure to nocodazole, then released into DY131 or DMSO control. Arrows denote cells of interest. B. Quantitation of time elapsed from chromatin condensation (prophase) to anaphase in MCF7 cells stably expressing GFP-H2B after release from nocodazole block into DY131 or DMSO control. $\mathrm{N}=4-11$ cells, one-way ANOVA with Tukey's post-test. 
us to test whether longer treatment causes mitotic catastrophe by disrupting centrosome number and/or spindle polarity. HCC1806 cells were treated with DY131 or DMSO for 24 $\mathrm{h}$, fixed, and stained for the centrosomal marker $\gamma$-tubulin, $\beta$-tubulin and DNA (Figure 9A-9C). While DMSO-treated mitotic cells contain two clearly separated $\gamma$-tubulin puncta indicative of properly oriented centrosomes flanking metaphase chromosomes, most DY131-treated HCC1806 cells have monopolar spindles indicative of 1 centrosome per cell and more disorganized metaphase plates or none at all. By contrast, MDA-MB-231 cells have significantly more multipolar spindles, with $\geq 3$ centrosomes per cell following DY131 treatment (Figure 9D). Altogether, these data suggest that DY131 treatment leads to catastrophic mitotic spindle defects that are likely responsible for the observed DiM.

\section{Endogenous ERRß2 localizes to the cytosol and centrosomes}

Zhou et al. showed in COS- 1 cells that exogenous ERR $\beta$ sf is a nuclear protein, while exogenous ERR $\beta 2$ is primarily found in the cytosol [26]. In HCC1806 cells transfected with these cDNAs and stained using splice variant-preferential monoclonal antibodies (cl.05 for ERR $\beta$ sf and cl.07 for ERR $\beta 2), E R R \beta s f$ is localized to the nucleus, while ERR $\beta 2$ is found in both the nucleus and cytosol (Figure 10A). We then used biochemical and imaging approaches to determine whether endogenous ERR $\beta$ sf and ERR $\beta 2$ are also localized to discrete cellular compartments. Subcellular fractionation shows that ERR $\beta 2$ is abundant in the cytosolic fraction, while ERR $\beta$ sf
A.

DMSO

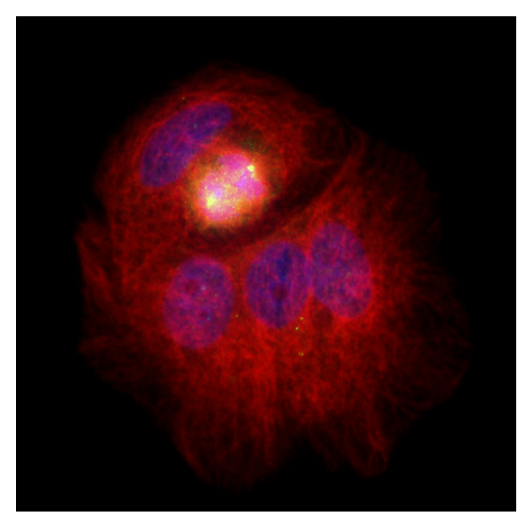

$\gamma$-tubulin $\beta$-tubulin DNA
B.

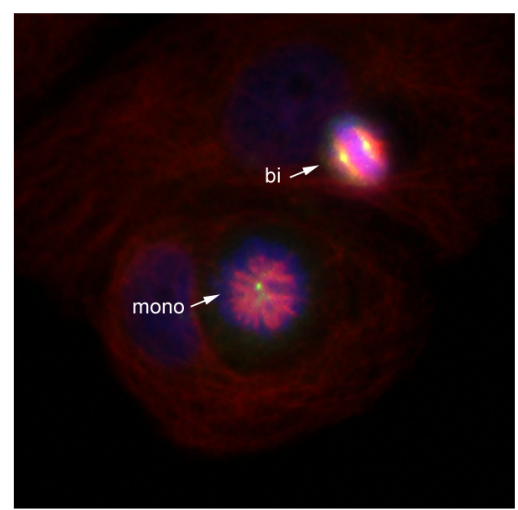

DY131

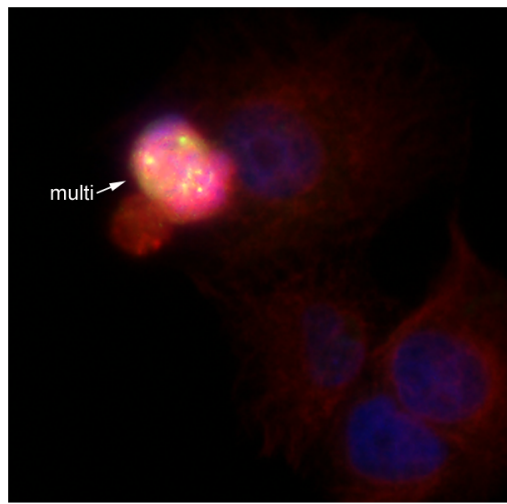

C. $\mathrm{HCC} 1806^{* * *} \mathrm{p}<0.0001$

DMSO

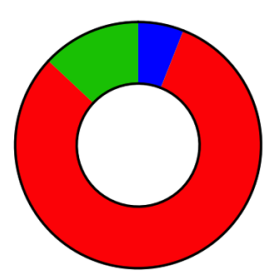

D. MDA-MB-231

DMSO

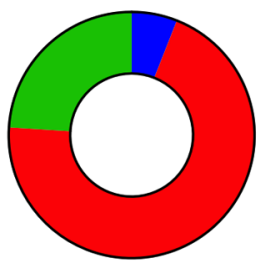

Monopolar

$\square$ Bipolar

$\square$ Multipola
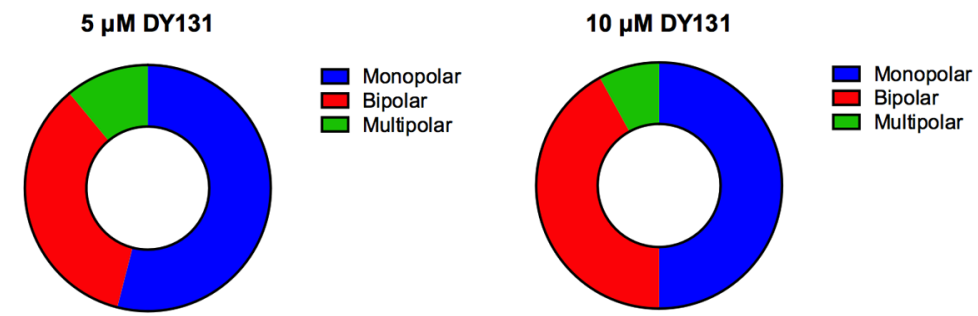

${ }^{* * *} p<0.0001$

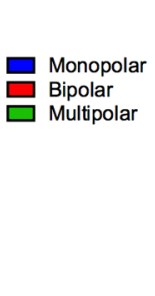

$5 \mu \mathrm{M}$ DY131

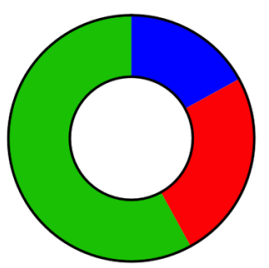

$10 \mu \mathrm{M}$ DY131

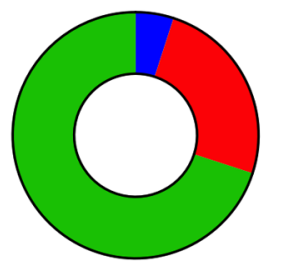

Bipolar

$\square$ Multipolar
Monopolar

Figure 9: DY131 causes monopolar and multipolar spindles. A. and B. HCC1806 were treated with DMSO and DY131 (5 uM) for $24 \mathrm{~h}$. The cells were fixed and stained for the centrosomal marker $\gamma$-tubulin, $\beta$-tubulin and DAPI. C. and D. Graphical representation of the fraction of mono-, bi- and multipolar spindles for HCC1806 and MDA-MB-231 cells treated with DY131 or DMSO control for $24 \mathrm{~h}$. $\mathrm{N}=3$ independent assays, chi squared test. 
is enriched in the nuclear pellet (Figure 10B). Confocal immunofluorescence microscopy for endogenous $\operatorname{ERR} \beta$ expression in HCC1806 (Figure 10C) and MDA-MB-231 breast cancer cells (Figure 10D) confirms that ERR $\beta$ sf is found in the nucleus of both cell lines. However, endogenous ERR $\beta 2$ exhibits diffuse staining throughout the cell with statistically significant enrichment in bright puncta that colocalize with $\gamma$-tubulin (upper right portion of each panel, arrows and inset of 10C and 10D, and Supplementary Figure S3). Centrosomal localization of endogenous ERR $\beta 2$ is consistent with delayed mitotic progression and the spindle defects observed upon DY131 treatment.

\section{DISCUSSION}

Liganded receptors have long been successful drug development targets, with selective estrogen and androgen receptor modulators key to the clinical management of hormone receptor-positive breast and prostate cancer for decades. The recent discovery that liver-X nuclear hormone receptor agonists are highly effective against metastatic melanoma [71] underscores the potential clinical utility of small molecules that target this and other [72] orphan nuclear receptors. Here we present evidence that i. a synthetic ligand for estrogen-related receptors $\beta$

\section{A. Transfected HCC1806}
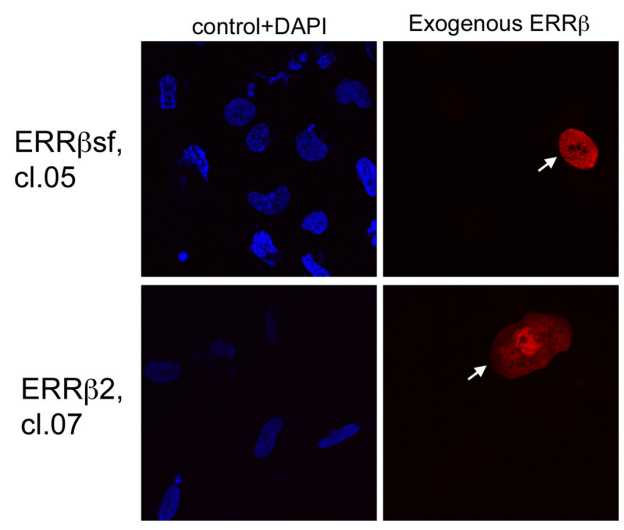

C. Endogenous HCC1806

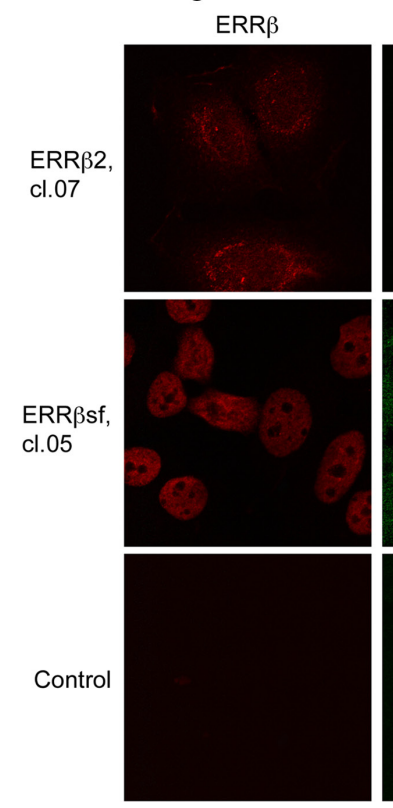

$\gamma$-tubulin

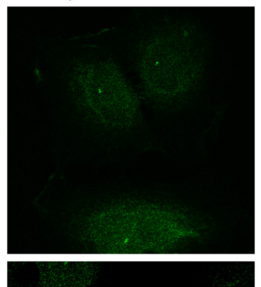

merge+DAPI
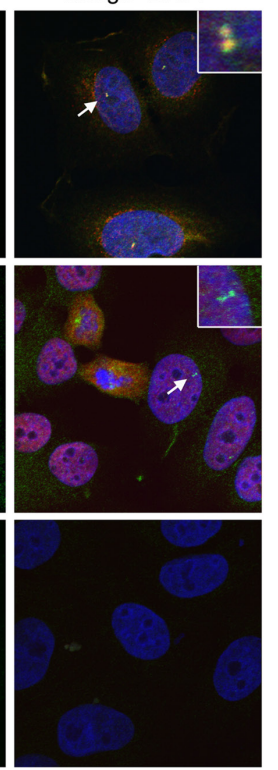

\section{B. Subcellular Fractionation}

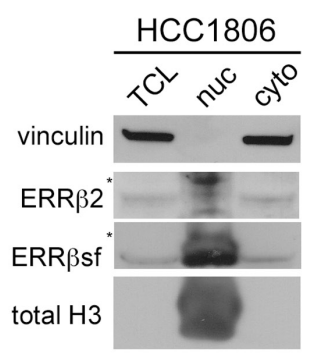

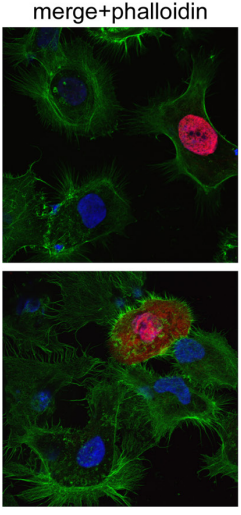

D. Endogenous MDA-MB-231

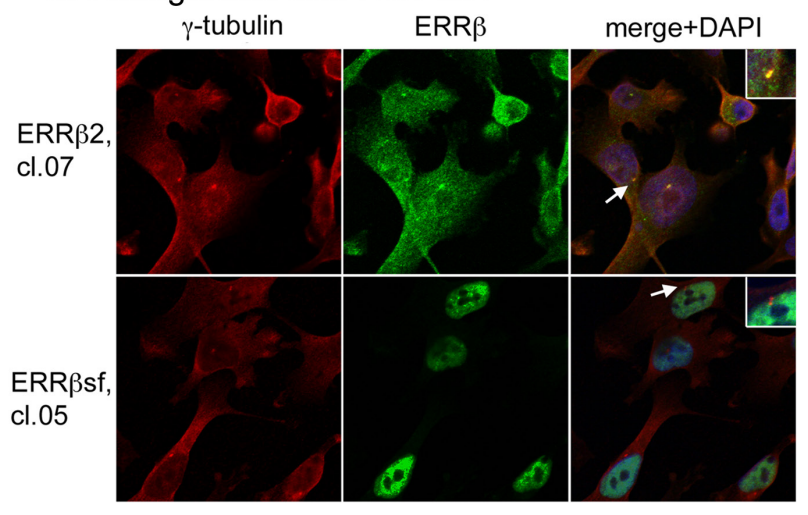

Figure 10: Endogenous ERRß2 localizes to the cytosol and centrosomes. A. Subcellular localization of exogenous ERR $\beta$ sf (cl.05, top) and ERR 32 (cl.07, bottom) together with DNA (DAPI) in HCC1806 cells transfected with the appropriate cDNA. Arrowheads denote transfected cells. Control + DAPI indicates cells stained only with secondary antibodies plus DAPI. Phall = phalloidin. B. REAP fractionation of $\mathrm{HCC} 1806$ cells followed by Western blot analysis of vinculin, ERR $\beta 2$, ERRßsf, and total Histone H3. * denotes nonspecific band in nuclear extracts. Lanes were loaded as follows: TCL, $40 \mu \mathrm{l}$; nuc, $20 \mu \mathrm{l}$; cyto, $40 \mu \mathrm{l}$. C. Subcellular localization of endogenous ERR 32 (top panels) or ERR $\beta$ sf (bottom panels) together with the centrosome marker $\gamma$-tubulin and DNA (DAPI) in HCC1806 cells. Insets show an expanded view of centrosomes identified by arrows. Control indicates cells stained only with secondary antibodies plus DAPI. D. MDA-MB-231 cells, same as in C. 
and $\gamma$ (DY131) is growth-inhibitory towards breast cancer cells, ii. the ERR $\beta 2$ splice variant is a cytosolic and centrosomal protein, and iii. DY131-mediated anti-mitotic activity is characterized by spindle polarity defects.

DY131 induces cell death in hormone receptorpositive and -negative breast cancer cell lines, while it has no significant cytotoxic effect on MCF10A nontransformed mammary epithelial cells (Figure 3 ). The cell death phenotype is characterized by features of apoptosis (Annexin V membrane staining and PARP cleavage). It is also accompanied by the induction of $\gamma \mathrm{H} 2 \mathrm{AX}$, historically an indicator of DNA double-strand breaks (DSBs) that has more recently emerged as an alternate measure of apoptosis $[55,56,73]$. $\gamma \mathrm{H} 2 \mathrm{AX}$ as a marker for DY131mediated apoptotic cell death rather than DNA damage is supported by two specific pieces of evidence: the lack of involvement of DNA damage-responsive kinases (ATM, ATR; (Figure 4)); and the requirement for an active p38 MAPK pathway (Figure 6), of which $\gamma \mathrm{H} 2 \mathrm{AX}$ is a known target [63-65].

In the present study, three of four breast cancer cell lines show a bimodal cell cycle arrest in response to DY131 (G1 at a lower concentration, G2/M at a higher concentration), with MDA-MB-231 cells exclusively undergoing G2/M arrest (Figure 5). Our studies in GBM [27] were the first to establish that the ERR $\beta$ sf and ERR $\beta 2$ splice variants have distinct cell cycle regulatory roles, with ERR $\beta$ sf mediating G1 arrest and the ERR $\beta 2$ isoform responsible for DY131-induced G2/M arrest. Here, we are able to shift the cell cycle arrest phenotype in MCF7 cells from $\mathrm{G} 1$ to $\mathrm{G} 2 / \mathrm{M}$ at a lower concentration of DY131 through exogenous expression of ERR $\beta 2$, as measured by an increase in Ser10 phosphorylation of histone H3 (Figure 7). These data further support the requirement for ERR $\beta 2$ in drug-induced G2/M arrest. In GBM, we showed that ERR $\beta$ sf is a transcriptionally active receptor that drives expression of $\mathrm{p} 21$, while ERR $\beta 2$ has no transcription factor activity and acts in a dominant-inhibitory fashion on the p21 promoter [27]. Here, we show that in breast cancer cells, ERR $\beta 2$ similarly cannot drive promoterreporter luciferase activity and suppresses ERR $\beta$ sf-driven transcription of ERRE-enhanced promoter-reporter constructs, in part through competition for coactivators like AIB1 (Figure 1). However, the mechanism(s) underlying the bimodal arrest profile in some breast cancer cells, which we did not observe in GBM, is/ are currently unknown. One hypothesis is that in breast cancer, there is a dose-dependent switch in splice variant dominance from ERR $\beta$ sf to ERR $\beta 2$ owing to changes in the abundance of receptors and/or coregulatory proteins. A more likely alternative is that ERR $\beta 2$ is the dominant splice variant at all times and the G1 arrest observed at lower concentrations of DY131 is due to mitotic slippage, while at higher concentrations the drug-induced block of mitotic transit is more robust, resulting in G2/M arrest and DiM. Mitotic slippage can be attributed to a failure of the spindle assembly checkpoint (SAC) and/or the anaphase promoting complex/cyclosome (APC/C-Cdh1, e.g. [74]). Our observation that treatment of nocodazole-released MCF7 cells with $5 \mu \mathrm{M}$ and $10 \mu \mathrm{M}$ DY131 causes the appearance of lagging chromosomes in metaphase (Figure 8 ) is suggestive of a drug-induced SAC and/or APC/CCdh1 defect.

Two novel findings of the present work are that endogenous ERR $\beta 2$ is a cytosolic protein that can localize to centrosomes, and treatment of breast cancer cells with DY131 leads to spindle polarity defects. Prior studies have evaluated the subcellular localization of untagged and epitope-tagged ERR $\beta$ splice variants in breast cancer and other cell lines, and have consistently shown that exogenous ERR $\beta$ sf is a nuclear protein $[26,38]$, which we also observe for the endogenous splice variant in MDA-MB-231 and HCC1806 cells. However, there are discrepancies in the reported subcellular localization of exogenous ERR $\beta 2$. Zhou et al. show broad nuclear and cytoplasmic localization of untagged ERR $\beta 2$ in most COS -1 cells, with only $\sim 30 \%$ cells showing predominantly nuclear staining [26]; this is similar to what we observe in HCC1806 cells transfected with exogenous ERR $\beta 2$, as well as endogenous ERR $\beta 2$ in HCC1806 and MDAMB-231 cells (Figure 10). By contrast, Bombail et al. [75] and Sengupta et al. [39] report exclusive nuclear localization of yellow fluorescent protein (YFP)-tagged "long form" receptor (ERR $\beta 2)$ in ovarian and breast cancer cells, respectively. We propose that these discordant results are due to altered localization of epitope tagged receptor, since we also observe that a SNAP-ERR $\beta 2$ fusion protein is only found in the nucleus (not shown). In MDA-MB-231 and HCC1806 breast cancer cells we observe endogenous ERR $\beta 2$ throughout the cytosol and in centrosomes, as shown by colocalization with $\gamma$-tubulin puncta adjacent to the nucleus. In addition, centrosome visualization (Figure 10C and 10D, Supplementary Figure $\mathrm{S} 3$ ) requires harsher post-permeabilization strategies like methanol [76], which may explain why ERR $\beta 2$ expression in this compartment has not been previously reported and why it is not evident in Figure 10A. To our knowledge, the only other orphan nuclear receptor that localizes to centrosomes is NR5A1 (steroidogenic factor-1, (SF1)), where its silencing causes centrosome duplication and chromosomal instability through a transcriptionindependent mechanism involving DNA-PK [77-79]. By contrast, exposure of MDA-MB-231 and HCC1806 cells to DY131 leads to the appearance of multipolar and monopolar spindles, respectively.

The ability of DY131 to induce spindle defects (Figure 9) and DiM positions ERR $\beta$, particularly the ERR $\beta 2$ splice variant, as a novel therapeutic target. Many aneuploid cells have more than two centrosomes, referred to as amplified or supernumerary centrosomes, and it is estimated that $\sim 80 \%$ of invasive breast tumors display this phenotype [80]. Centrosome amplification 
is common in cellular models of HER2-enriched breast cancer, and in this setting can also drive cancer cell invasion and migration [81, 82]. However, multipolar spindles do not support proper bipolar division, and their presence can cause chromosome missegregation and cell death during or immediately following mitosis [83, 84]. This has recently been shown to be the primary in vivo mechanism for paclitaxel-induced breast cancer cell death [85]. To avoid apoptosis triggered by centrosome amplification, cancer cells have evolved ways to cluster or group these extra centrosomes together during cell division [86]. These clustering mechanisms also present a therapeutic opportunity, and centrosome declustering drugs have been proposed as alternatives to conventional antimitotic therapies in breast and other cancers [8-11]. Whether DY131 is a centrosome declustering agent or leads to the appearance of multipolar spindles by other means (or both) remains to be determined. MDA-MB-231 cells have supernumerary centrosomes and are sensitive to known centrosome declustering agents (e.g. [10, 11]), but only $\sim 35 \%$ of a given population of these cells have clustered centrosomes [86]. It should also be noted that many centrosome declustering drugs can also cause centrosome amplification [10]. Further studies will be required to establish precisely how DY131 causes spindle defects, and why this can manifest as either multipolar or monopolar spindles.

Centrosome amplification is known to associate with poor outcome in TNBC [87], and we postulate that if ligand-mediated activation of ERR $\beta 2$ leads to mitotic arrest, spindle polarity defects, and DiM in cell line models of TNBC, expression of this splice variant should correlate with improved outcome in TNBC clinical specimens. We performed meta-analysis [88] of publicly available gene expression data from ER-/HER2- clinical specimens classified as basal [89] arrayed on the Affymetrix U133 Plus 2.0 platform, which has two ESRRB probesets that detect different combinations of transcript variants (Supplementary Figure S4). The probeset corresponding to a third splice variant not specifically studied here $($ ERR $\beta-\Delta 10)$ is not significantly associated with improved recurrence free survival (RFS) and distant metastasis freesurvival (DMFS, not shown), while the probeset that can detect both ERR $\beta 2$ and ERR $\beta-\Delta 10$ shows a significant positive correlation with longer RFS (hazard ratio 0.56 , log-rank $\mathrm{p}=0.00092$ ) and DMFS (hazard ratio 0.48, $\log$-rank $\mathrm{p}=0.035)$. No probesets that can detect ERR $\beta$ sf (alone or in combination with others) are available on this Affymetrix platform. Garattini et al.'s recent analysis of nuclear receptor superfamily expression in The Cancer Genome Atlas (TCGA) breast cancer RNAseq data shows that total ESRRB expression (referred to in the manuscript as NR3B2) is significantly reduced in breast tumors vs. normal breast tissue, with lowest expression in the Luminal B and Basal-Like molecular subtypes [90]. While preliminary, these data suggest that ERR $\beta 2$ may be a good prognostic factor in TNBC, and are consistent with the findings we present here that implicate the activated ERR $\beta 2$ splice variant as a potent inhibitor of mitotic progression in breast cancer cells, including triple negative models.

\section{MATERIALS AND METHODS}

\section{Cell culture}

MCF10A non-transformed mammary epithelial cells, and MCF7 and MDA-MB-231 breast cancer cells, were obtained from the Lombardi Comprehensive Cancer Center (LCCC) Tissue Culture Shared Resource. HCC1806 and MDA-MB-468 breast cancer cells were purchased from ATCC (Manassas, VA). Cells routinely tested negative for Mycoplasma spp., and were fingerprinted by the Tissue Culture Shared Resource to verify their authenticity using the 9 standard STR loci and Y chromosome-specific amelogenin. All cells were maintained in a humidified incubator with 95\% air: 5\% carbon dioxide. MCF7 and MDA-MB-231 cells were grown in improved minimal essential media (IMEM; Life Technologies, Grand Island, NY) supplemented with 5\% heat-inactivated fetal bovine serum (FBS, purchased from the LCCC Tissue Culture Shared Resource). HCC1806 and MDA-MB-468 cells were cultured in IMEM with $10 \%$ FBS. MCF10A cells were grown in a 1:1 mixture of Ham's F12: Dulbecco's modified essential media (DMEM) supplemented with $20 \mathrm{ng} / \mathrm{ml}$ epidermal growth factor (EGF), $10 \mu \mathrm{g} / \mathrm{ml}$ insulin, $0.5 \mu \mathrm{g} / \mathrm{ml}$ hydrocortisone, 100 $\mathrm{ng} / \mathrm{ml}$ cholera toxin, and 5\% horse serum (all purchased from the LCCC Tissue Culture Shared Resource).

\section{General reagents}

Geneticin (G418, Life Technologies) was used at a final concentration of $1.2 \mathrm{mg} / \mathrm{ml}$ for MCF7 cells stably expressing fluorescent histone H2B. ERR $\beta$ agonists DY131 and GSK4716, and the p38 inhibitor SB203580 (Tocris Bioscience, Ellisville, MO), were dissolved in dimethyl sulfoxide (DMSO; Sigma Aldrich, St. Louis, $\mathrm{MO}$ ) at a concentration of $10 \mathrm{mM}$, stored at $-20^{\circ} \mathrm{C}$, and used at the indicated concentrations. The microtubule inhibitor nocodazole (Sigma Aldrich), Smoothened inhibitors vismodegib and cyclopamine (kind gifts from Dr. Insoo Bae), paclitaxel (generously provided by Dr. Robert Clarke), flavopiridol (kind gift from Dr. Christopher Albanese), and the ATM inhibitor KU55933 (generously provided by Dr. Gil Palchik) were also prepared as concentrated stocks in DMSO, stored at $-20^{\circ} \mathrm{C}$ or $4^{\circ} \mathrm{C}$ (nocodazole), and used at the indicated concentrations. Doxorubicin (kind gift from Dr. Robert Clarke), mitoxantrone (generously provided by Dr. Rabindra Roy), and arsenic trioxide (ATO, [54]) were prepared as concentrated stocks in molecular biology- 
grade water, stored at $-20^{\circ} \mathrm{C}$, and used at the indicated concentrations. Human ERR $\gamma$ purified protein (transcript variant 2), was purchased from Origene (Rockville, MD).

\section{Plasmids and transfection}

The ERE-luciferase, ERRE-luciferase (Addgene \#37851), 8xGLI1-luciferase, and pRL-SV40-Renilla promoter-reporter constructs have been previously described $[42,43,54,91]$. The pSG5 empty vector, ERR $\gamma$, ERRßsf (Addgene \#52188), ERRß2 (Addgene \#52186), and EGFP-GLI1 expression constructs have also been published previously $[27,43,54,92]$. FLAG-AIB1 was generously provided by Dr. Anna T. Riegel [36]. H2B-GFP was a gift from Dr. Geoff Wahl (Addgene plasmid \# 11680) [67]. Plasmids were introduced to cells using either jetPRIME (Polyplus Transfection, Ilkirch, France) or Lipofectamine LTX (Life Technologies) according to manufacturer's instructions. After 4-5 h, transfection complexes were removed and fresh media were added as appropriate.

\section{Dual-luciferase promoter-reporter assays}

Cells were seeded into 24-well plastic tissue culture dishes (35,000 per well for MDA-MB-231; 50,000-75,000 per well for MCF7) on day 0 , transfected on day 1 with a total of $500 \mathrm{ng}$ DNA/well (100-200 ng receptor, EGFPGLI1, or AIB1 expression plasmid; 195-240 ng luciferase reporter plasmid; 5-10 ng Renilla control), treated 4-5 h posttransfection for 18-24 $\mathrm{h}$ with the indicated compounds, and harvested on day 2 for dual-luciferase assay as described in [27]. Luciferase activity was normalized to Renilla activity. Each experiment was performed in triplicate.

\section{Cell proliferation assays}

Cells were seeded into 3, 96-well plastic tissue culture dishes per line at 1,000 cells per well on day 0 . On day 1 , each plate was treated with the indicated concentrations of DY131. Plates were re-dosed every 3 days and stained on days 3 or 4,7 or 8 , and 10 or 11 . To stain, one plate per line was rinsed once with $1 \mathrm{X}$ Phosphate-Buffered Saline (PBS) and incubated with a solution of $0.5 \% \mathrm{w} / \mathrm{v}$ crystal violet (Sigma Aldrich) dissolved in $25 \%$ methanol: $75 \%$ water at $4^{\circ} \mathrm{C}$ for 10 minutes. Excess stain was removed and each plate was washed 5-6 times with deionized $\mathrm{H} 2 \mathrm{O}$ and allowed to air dry completely. Stained cells were rehydrated in a $0.1 \mathrm{M}$ sodium citrate buffer dissolved in 50\% ethanol: $50 \%$ water, then read on a plate reader at an absorbance of $550 \mathrm{~nm}$. Each experimental condition was performed in six replicate wells.

\section{Colony formation assays}

On day 0, 150 (MDA-MB-231) or 200 (MCF7) cells were seeded per well in 4 wells of a 12-well plastic tissue culture dish. The following day, indicated concentrations of DY131 were added for 18-24 h. On day 2, drugcontaining media were removed, wells were washed with $1 \mathrm{X}$ PBS, and fresh media (no drug) was added to the wells. Cells were cultured in the absence of drug for an additional $13 \mathrm{~d}$, changing media twice, before staining with crystal violet solution as above.

\section{Total cell lysis and subcellular fractionation}

Preparation of whole cell extracts in radioimmunoprecipitation assay (RIPA) buffer supplemented with protease and phosphatase inhibitors from cells seeded in 6-well plastic tissue culture dishes and (as appropriate) transfected or treated was carried out as in [27]. Samples to be probed for expression or post-translational modification of histones were gently sonicated prior to protein quantification (30\% output, 3 seconds on $/ 3$ seconds off for a total of 3 times). Subcellular fractionation was carried out using a modification of the REAP method [93]. Cells were washed three times with cold PBS, aspirating in between washes. Then $1 \mathrm{~mL}$ of cold PBS was added to the $10 \mathrm{~cm}$ dish, and cells were scraped into an Eppendorf tube and centrifuged at $4^{\circ} \mathrm{C}$ in a microcentrifuge for 5 minutes at $5000 \mathrm{x} \mathrm{g}$. On ice, $1 \mathrm{~mL}$ of $0.4 \%$ Nonidet P 40 substitute was added to resuspend the cell pellet. $300 \mu \mathrm{L}$ of the total cell lysate was immediately taken from the resuspension and and centrifuged at 10,000 $\mathrm{x} g$ for 2 minutes at $4^{\circ} \mathrm{C}$. The supernatant was added to $100 \mu \mathrm{L} 4 \mathrm{X}$ loading buffer and boiled at $99{ }^{\circ} \mathrm{C}$ for 8 minutes. The remainder of the lysate was incubated on ice for 3 minutes, then centrifuged at $4^{\circ} \mathrm{C}$ for 5 minutes at $5000 \times \mathrm{g}$. Another $300 \mu \mathrm{L}$ of the supernatant was collected as the cytosolic fraction and added to $100 \mu \mathrm{L}$ of $4 \mathrm{X}$ loading buffer and then boiled at $99^{\circ} \mathrm{C}$ for 8 minutes. The nuclear pellet was then resuspended in $1 \mathrm{~mL}$ of $0.4 \%$ Nonidet P 40 substitute and centrifuged at $4{ }^{\circ} \mathrm{C}$ for 2 minutes at 10,000 $\mathrm{xg}$. The supernatant was discarded and the pellet was resuspended in $80 \mu \mathrm{L}$ of $4 \mathrm{X}$ loading buffer and boiled at $99^{\circ} \mathrm{C}$ for 10 minutes.

\section{Western blotting and antibodies}

Following polyacrylamide gel electrophoresis and protein transfer, nitrocellulose membranes were blocked in $5 \%$ nonfat dry milk*** dissolved in Tris-Buffered Saline with Tween-20 (TBST), then probed overnight at $4{ }^{\circ} \mathrm{C}$ with the following primary antibodies in TBST: ERRbeta \#PP-H6707-00 (cl.07) 1:250 - 1:500 and \#PP-H6705-00 (cl.05) 1:500 - 1:750 (R\&D Systems, Minneapolis, MN); PARP \#9542 1:1000, phospho Ser139 $(\gamma)$ histone H2A. X \#9718 1:1000, ***total histone H2A. X \#2595 1:1000, phospho Ser1981 ATM \#5883 1:500, phospho Ser428 ATR \#2853 1:500, phospho Thr68 Chk2 \#2197 1:500, phospho Ser345 Chk1 \#2348 1:500, phospho Ser10 histone H3 \#3377 1:1000, total histone H3 \#9715 1:1000, phospho Thr180/Tyr182 p38 MAPK \#9216 1:250, p38 \#9212 
1:500, vinculin \#13901 1:1000 (Cell Signaling, Danvers, MA). All membranes were re-probed with $\beta$-actin (Sigma \#A5316 1:5000 - 1:10,000) as a loading control for $\geq 1$ $\mathrm{h}$ at room temperature or overnight at $4^{\circ} \mathrm{C}$. Horseradish peroxidase enzyme-conjugated anti-mouse or anti-rabbit whole immunoglobulin (IgG) secondary antibodies (GE \#NXA931 and \#NA934V, respectively, Buckinghamshire, U.K.) were used at 1:5000 for $\geq 1 \mathrm{~h}$ at room temperature, followed by enhanced chemiluminescence (ECL, Denville Scientific, Holliston, MA) as in [27]. ***Membranes to be probed for total histone H2A. X were blocked in 5\% horse serum in TBST rather than milk.

\section{Cell cycle analyses}

On day 0 , cells were seeded at $100,000-150,000$ cells per well in 6-well plastic tissue culture dishes one day prior to treatment with the indicated concentrations of drug. For experiments with the p38 inhibitor SB203580, cells were pretreated with the compound for $1 \mathrm{~h}$ before the addition of DY131. The following day (day 2), cells were collected, ethanol-fixed, stained with propidium iodide, and analyzed for cell subG1 (fragmented) DNA content and cell cycle profile as in [27].

\section{Apoptosis/necrosis assays}

Cells were seeded and drug-treated as described above for cell cycle analyses. $12 \mathrm{~h}$ (MDA-MB-231), $16 \mathrm{~h}$ (HCC1806), or 24 h (MCF10A, MCF7, MDA-MB-468) post-treatment, cells were collected and stained with fluorescein isothiocyanate (FITC)-conjugated Annexin V and propidium iodide, and analyzed by flow cytometry as in [27].

\section{BIAcore DNA binding assays}

DNA binding studies were performed in a Biacore T100 system (BIAcore, Uppsala, Sweden) as published previously [94, 95]. Briefly, the affinity of DY131, GSK4716, and mitoxantrone for DNA was tested using a 50-mer oligonucleotide:

5'-TCGAGGATCCTGAGCTCGAGTCGACGATC GCGAATTCTGCGGATCCAAGC-3'

The oligonucleotide was biotinylated and immobilized on streptavidin-coated C1 BIAcore chips as single-stranded DNA or in duplex with the reverse complement oligonucleotide as double-stranded DNA. Relative Unit (RU) values were recorded with three, 60s injections of each compound $(15 \mu \mathrm{M})$ in a binding buffer containing $10 \mathrm{mM}$ HEPES-KOH, $\mathrm{pH}$ 7.6, $90 \mathrm{mM} \mathrm{KCl}$, and $0.05 \%$ surfactant P20 (BIAcore).

\section{Live-cell confocal microscopy}

MCF7-GFP-H2B cells were seeded into 6-well glass-bottom tissue culture dishes at 150,000 cells per well one day before being synchronized by exposure to $100 \mathrm{nM}$ nocodazole for $18-22 \mathrm{~h}$. The following day, plates were brought to the LCCC Microscopy \& Imaging Shared Resource's Nikon Eclipse TE-300 Inverted Spinning Disk Confocal Microscope System with heated and humidified environmental chamber and $\mathrm{CO}_{2}$ control. Cells were allowed to equilibrate in the chamber for $30-45 \mathrm{~m}$, then five fields per condition with $\geq 1$ cells per field with condensed chromatin were selected for imaging. Nocodazole-containing media were carefully removed, cells were washed twice with warm PBS, then immediately exposed to media containing DMSO vehicle control, $5 \mu \mathrm{M}$ DY131, $10 \mu \mathrm{M}$ DY131, $10 \mu \mathrm{M}$ flavopiridol, or $250 \mathrm{nM}$ paclitaxel. Images were acquired using a 20X/ 0.5 N.A. Plan Fluor Nikon objective. The microscope is coupled with a Perkin Elmer VoX core unit for spinning disk confocal imaging and image capture was via an EMCCD cooled $1 \mathrm{~K}$ X $1 \mathrm{~K}$ CCD camera and Volocity Ver. 6.3 Acquisition software. An AOTF-controlled $488 \mathrm{~nm}$ laser diode was used for multi-well, live imaging of nuclear GFP-H2B. 10 image z-stacks at $1 \mu \mathrm{m}$ spacing were obtained for each time point for multiple fields of view via a Prior Pro Scan motorized x, y, z stage.

\section{Fixed-cell confocal microscopy}

For spindle polarity studies, cells were seeded onto $18 \mathrm{~mm}$ glass coverslips placed in 12-well plastic tissue culture dishes at 70,000 cells per well two days prior to staining, allowing for $24 \mathrm{~h}$ treatment with DY131 or DMSO control prior to fixation. For exogenous ERR $\beta$ subcellular localization studies, 200,000 - 300,000 cells per well were seeded two days prior to staining, allowing for 18-20 $\mathrm{h}$ transfection with ERR $\beta$ sf or ERR $\beta 2$ cDNAs. For endogenous ERR $\beta / \gamma$-tubulin co-localization studies, 85,000 cells per well were seeded one day prior to staining. Media were removed and cells were fixed and permeabilized in $3.2 \%$ paraformaldehyde with $0.2 \%$ Triton X-100 in PBS for 5 minutes at room temperature. For endogenous ERR $\beta / \gamma$-tubulin co-localization studies, coverslips were further permeabilized in cold absolute methanol at $-20^{\circ} \mathrm{C}$ for 10 minutes. Following three washes with PBS, coverslips were inverted onto one drop $(\sim 100 \mu \mathrm{l})$ of primary antibody in antibody diluent $(0.1 \%$ gelatin with $10 \%$ normal donkey serum in PBS) on strips of parafilm and incubated as shown in the table found in the Supplementary Materials. Coverslips were stained first for ERR $\beta$ sf or ERR $\beta 2$, where appropriate, then for $\gamma$-tubulin at room temperature. Antibody controls were incubated in antibody diluent only. After carefully lifting each coverslip and washing three times with PBS, coverslips were inverted onto one drop of the appropriate secondary antibody, DAPI dihydrochloride, and (where appropriate) ActiStain-488-phalloidin (Cytoskeleton, Denver, CO) in antibody diluent, then incubated in the dark at room temperature as shown in the Supplementary Materials. Coverslips were again washed with PBS, 
then gently dipped twice into molecular biology-grade water before inversion onto one drop of FLUOROGEL (Electron Microscopy Sciences, Hatfield, PA) before being allowed to air-dry in the dark for at least 10 minutes. Slides were stored at $4^{\circ} \mathrm{C}$ until image collection on the LCCC Microscopy \& Imaging Shared Resource's Zeiss LSM510/META/NLO multi-photon microscope using the settings shown in the table found in the Supplementary Materials.

\section{Image and statistical analyses}

Photoshop CreativeSuite 5.1 was used to assemble figures, FIJI (http://fiji.sc/Fiji) was used to perform densitometry on scanned Western blots, and Volocity 3D Image Analysis Software (PerkinElmer, Waltham, MA) was used to analyze confocal microscopy data (see Supplementary Materials). All statistical analyses, except those in Supplementary Figure S4, were performed in Prism 6.0 (Graphpad, San Diego, CA), and are specified in the figure legends. All data are presented as the mean \pm standard deviation (S.D.), with the exception of Figure 9C and 9D, where data are depicted as 'parts of the whole' plots. Statistical significance is defined as a $P$ value of $\leq 0.05 . * \mathrm{p} \leq 0.05, * * \mathrm{p} \leq 0.01, * * * \mathrm{p} \leq 0.001, * * * * \mathrm{p} \leq 0.0001$.

\section{ACKNOWLEDGMENTS}

We are very grateful to Yasemin Saygideger Kont, Peter Johnson, and Alex Joseph for their assistance with BIAcore, immunofluorescence microscopy, and flow cytometry experiments, respectively. We would also like to thank Drs. Christopher Albanese, Maria Laura Avantaggiati, Insoo Bae, Robert Clarke, Karen Creswell, Michael Johnson, Gil Palchik, Anna Riegel, Hillary Stires, Jeffrey Toretsky, Anton Wellstein, and Ronit Yarden for sharing reagents, helpful discussions and intellectual insights, and/or critical reading of the manuscript.

\section{CONFLICTS OF INTEREST}

The authors have no potential conflicts of interest to disclose.

\section{GRANT SUPPORT}

This work was generously supported by pilot funds from Partners in Research (partnersinresearch. gumc.georgetown.edu) awarded to RBR, developmental funds from the Lombardi Comprehensive Cancer Center (LCCC) Cancer Center Support Grant awarded to RBR (P30 CA051008; PI Dr. Louis M. Weiner), and R21 CA191444 awarded to RBR. Fellowship funding was provided by the LCCC Tumor Biology Training Grant (MMH and DMT; T32 CA009686, PI Dr. Anna T. Riegel) and the Post Baccalaureate Training in Cancer Health
Disparities Research Grant from Susan G. Komen for the Cure (MMH and AIF; PBTDR1222836, PI Dr. Lucile Adams-Campbell). Technical services were provided by the Flow Cytometry \& Cell Sorting, Genomics \& Epigenomics, Microscopy \& Imaging, and Tissue Culture Shared Resources, which were also supported in part by P30 CA051008. The content of this article is the sole responsibility of the authors and does not represent the official views of the National Cancer Institute, the National Institutes of Health, or Susan G. Komen for the Cure.

\section{REFERENCES}

1. DeSantis C, Siegel R, Bandi P, Jemal A: Breast cancer statistics, 2011. CA Cancer J Clin 2011;61:409-418.

2. Jemal A, Bray F, Center MM, Ferlay J, Ward E, Forman D: Global cancer statistics. CA Cancer J Clin 2011;61:69-90.

3. Kohler BA, Sherman RL, Howlader N, Jemal A, Ryerson AB, Henry KA, Boscoe FP, Cronin KA, Lake A, Noone AM, Henley SJ, Eheman CR, Anderson RN, Penberthy L: Annual report to the nation on the status of cancer, 1975-2011, featuring incidence of breast cancer subtypes by race/ethnicity, poverty, and state. J Natl Cancer Inst 2015;107:djv048.

4. Le Du F, Eckhardt BL, Lim B, Litton JK, Moulder S, MericBernstam F, Gonzalez-Angulo AM, Ueno NT: Is the future of personalized therapy in triple-negative breast cancer based on molecular subtype? Oncotarget 2015;6:1289012908. doi:10.18632/oncotarget.3849.

5. Galluzzi L, Vitale I, Abrams JM, Alnemri ES, Baehrecke EH, Blagosklonny MV, Dawson TM, Dawson VL, El-Deiry WS, Fulda S, Gottlieb E, Green DR, Hengartner MO, et al. Molecular definitions of cell death subroutines: Recommendations of the nomenclature committee on cell death 2012. Cell Death Differ 2012;19:107-120.

6. Vitale I, Galluzzi L, Castedo M, Kroemer G: Mitotic catastrophe: A mechanism for avoiding genomic instability. Nat Rev Mol Cell Biol 2011;12:385-392.

7. Chan KS, Koh CG, Li HY: Mitosis-targeted anti-cancer therapies: Where they stand. Cell Death Dis 2012;3:e411.

8. Kawamura E, Fielding AB, Kannan N, Balgi A, Eaves CJ, Roberge M, Dedhar S: Identification of novel small molecule inhibitors of centrosome clustering in cancer cells. Oncotarget 2013;4:1763-1776. doi:10.18632/oncotarget.1198.

9. Pannu V, Rida PC, Ogden A, Turaga RC, Donthamsetty S, Bowen NJ, Rudd K, Gupta MV, Reid MD, Cantuaria G, Walczak CE, Aneja R: Hset overexpression fuels tumor progression via centrosome clustering-independent mechanisms in breast cancer patients. Oncotarget 2015;6:6076-6091. doi:10.18632/oncotarget.3475.

10. Ogden A, Cheng A, Rida PC, Pannu V, Osan R, Clewley R, Aneja R: Quantitative multi-parametric evaluation of centrosome declustering drugs: Centrosome amplification, mitotic phenotype, cell cycle and death. Cell Death Dis 2014;5:e1204. 
11. Pannu V, Rida PC, Celik B, Turaga RC, Ogden A, Cantuaria G, Gopalakrishnan J, Aneja R: Centrosome-declustering drugs mediate a two-pronged attack on interphase and mitosis in supercentrosomal cancer cells. Cell Death Dis 2014;5:e1538.

12. Topham C, Tighe A, Ly P, Bennett A, Sloss O, Nelson L, Ridgway RA, Huels D, Littler S, Schandl C, Sun Y, Bechi B, Procter DJ, Sansom OJ, Cleveland DW, Taylor SS: Myc is a major determinant of mitotic cell fate. Cancer Cell 2015;28:129-140.

13. Wang L, Zuercher WJ, Consler TG, Lambert MH, Miller AB, Orband-Miller LA, McKee DD, Willson TM, Nolte RT: X-ray crystal structures of the estrogen-related receptorgamma ligand binding domain in three functional states reveal the molecular basis of small molecule regulation. J Biol Chem 2006;281:37773-37781.

14. Zuercher WJ, Gaillard S, Orband-Miller LA, Chao EY, Shearer BG, Jones DG, Miller AB, Collins JL, McDonnell DP, Willson TM: Identification and structure-activity relationship of phenolic acyl hydrazones as selective agonists for the estrogen-related orphan nuclear receptors errbeta and errgamma 2 7337. JMedChem 2005;48:3107-3109.

15. Yu DD, Forman BM: Identification of an agonist ligand for estrogen-related receptors errbeta/gamma 1. BioorgMedChemLett 2005;15:1311-1313.

16. Gantner ML, Hazen BC, Conkright J, Kralli A: Gadd45 $\gamma$ regulates the thermogenic capacity of brown adipose tissue. Proc Natl Acad Sci U S A 2014;111:11870-11875.

17. Gaillard S, Grasfeder L, Haeffele C, Lobenhofer E, Chu T, Wolfinger R, Kazmin D, Koves T, Muoio D, Chang C, McDonnell D: Receptor-selective coactivators as tools to define the biology of specific receptor-coactivator pairs. Mol Cell 2006;24:797-803.

18. Kamei Y, Ohizumi H, Fujitani Y, Nemoto T, Tanaka T, Takahashi N, Kawada T, Miyoshi M, Ezaki O, Kakizuka A: Ppargamma coactivator 1beta/err ligand 1 is an err protein ligand, whose expression induces a high-energy expenditure and antagonizes obesity. ProcNatlAcadSciUSA 2003;100:12378-12383.

19. Kidani T, Kamei S, Miyawaki J, Aizawa J, Sakayama K, Masuno H: Bisphenol a downregulates akt signaling and inhibits adiponectin production and secretion in 3t3-11 adipocytes. J Atheroscler Thromb 2010;17:834-843.

20. Papp B, Plath K: Pluripotency re-centered around esrrb. EMBO J 2012;31:4255-4257.

21. Percharde M, Lavial F, Ng JH, Kumar V, Tomaz RA, Martin N, Yeo JC, Gil J, Prabhakar S, Ng HH, Parker MG, Azuara V: Ncoa3 functions as an essential esrrb coactivator to sustain embryonic stem cell self-renewal and reprogramming. Genes Dev 2012;26:2286-2298.

22. Feng B, Jiang J, Kraus P, Ng JH, Heng JC, Chan YS, Yaw LP, Zhang W, Loh YH, Han J, Vega VB, Cacheux-Rataboul V, Lim B, Lufkin T, Ng HH: Reprogramming of fibroblasts into induced pluripotent stem cells with orphan nuclear receptor esrrb. Nat Cell Biol 2009;11:197-203.
23. van der Laan S, Golfetto E, Vanacker JM, Maiorano D: Cell cycle-dependent expression of dub3, nanog and the p160 family of nuclear receptor coactivators (ncoas) in mouse embryonic stem cells. PLoS One 2014;9:e93663.

24. van der Laan S, Tsanov N, Crozet C, Maiorano D: High dub3 expression in mouse escs couples the g1/s checkpoint to pluripotency. Mol Cell 2013;52:366-379.

25. Yu S, Wong YC, Wang XH, Ling MT, Ng CF, Chen $\mathrm{S}$, Chan FL: Orphan nuclear receptor estrogen-related receptor-beta suppresses in vitro and in vivo growth of prostate cancer cells via p21(waf1/cip1) induction and as a potential therapeutic target in prostate cancer. Oncogene 2008;27:3313-3328.

26. Zhou W, Liu Z, Wu J, Liu JH, Hyder SM, Antoniou E, Lubahn DB: Identification and characterization of two novel splicing isoforms of human estrogen-related receptor beta. J Clin Endocrinol Metab 2006;91:569-579.

27. Heckler MM, Riggins RB: Err $\beta$ splice variants differentially regulate cell cycle progression. Cell Cycle 2015;14:31-45.

28. Vanacker JM, Maiorano D: Checking the cycle by err $\beta$ splice variants. Cell Cycle 2015;14:1492-1493.

29. Gearhart M, Holmbeck S, Evans R, Dyson H, Wright P: Monomeric complex of human orphan estrogen related receptor-2 with dna: A pseudo-dimer interface mediates extended half-site recognition. J Mol Biol 2003;327:819-832.

30. Sanyal S, Matthews J, Bouton D, Kim HJ, Choi HS, Treuter E, Gustafsson JA: Deoxyribonucleic acid response element-dependent regulation of transcription by orphan nuclear receptor estrogen receptor-related receptor gamma. MolEndocrinol 2004;18:312-325.

31. Akter MH, Chano T, Okabe H, Yamaguchi T, Hirose F, Osumi T: Target specificities of estrogen receptor-related receptors: Analysis of binding sequences and identification of rb1-inducible coiled-coil 1 (rb1 cc1) as a target gene. J Biochem 2008;143:395-406.

32. Deblois G, Hall J, Perry M, Laganière J, Ghahremani M, Park M, Hallett M, Giguère V: Genome-wide identification of direct target genes implicates estrogen-related receptor alpha as a determinant of breast cancer heterogeneity. Cancer Res 2009;69:6149-6157.

33. Huppunen J, Wohlfahrt G, Aarnisalo P: Requirements for transcriptional regulation by the orphan nuclear receptor errgamma. MolCell Endocrinol 2004;219:151-160.

34. Castet A, Herledan A, Bonnet S, Jalaguier S, Vanacker JM, Cavailles V: Receptor-interacting protein 140 differentially regulates estrogen receptor-related receptor transactivation depending on target genes. Molecular Endocrinology 2006;20:1035-1047.

35. Lonard DM, Lanz RB, O’Malley BW: Nuclear receptor coregulators and human disease. EndocrRev 2007;28:575-587.

36. Reiter R, Wellstein A, Riegel AT: An isoform of the coactivator aib1 that increases hormone and growth factor 
sensitivity is overexpressed in breast cancer. JBiolChem 2001;276:39736-39741.

37. Ariazi EA, Clark GM, Mertz JE: Estrogen-related receptor alpha and estrogen-related receptor gamma associate with unfavorable and favorable biomarkers, respectively, in human breast cancer. Cancer Res 2002;62:6510-6518.

38. Tanida T, Matsuda KI, Yamada S, Hashimoto T, Kawata M: Estrogen-related receptor $\beta$ reduces the subnuclear mobility of estrogen receptor $\alpha$ and suppresses estrogen-dependent cellular function. J Biol Chem 2015;290:12332-12345.

39. Sengupta D, Bhargava DK, Dixit A, Sahoo BS, Biswas S, Biswas G, Mishra SK: Err $\beta$ signalling through fst and bcas2 inhibits cellular proliferation in breast cancer cells. Br J Cancer 2014;110:2144-2158.

40. Eichner LJ, Perry MC, Dufour CR, Bertos N, Park M, St-Pierre J, Giguère V: Mir-378(*) mediates metabolic shift in breast cancer cells via the pgc-1 $\beta /$ err $\gamma$ transcriptional pathway. Cell Metab 2010;12:352-361.

41. Tiraby C, Hazen BC, Gantner ML, Kralli A: Estrogenrelated receptor gamma promotes mesenchymal-toepithelial transition and suppresses breast tumor growth. Cancer Res 2011;71:2518-2528.

42. Heckler MM, Thakor H, Schafer CC, Riggins RB: Erk/ mapk regulates erry expression, transcriptional activity and receptor-mediated tamoxifen resistance in er+ breast cancer. FEBS J 2014;281:2431-2442.

43. Riggins RB, Lan JP, Zhu Y, Klimach U, Zwart A, Cavalli LR, Haddad BR, Chen L, Gong T, Xuan J, Ethier SP, Clarke R: Errgamma mediates tamoxifen resistance in novel models of invasive lobular breast cancer. Cancer Res 2008;68:8908-8917.

44. Ijichi N, Shigekawa T, Ikeda K, Horie-Inoue K, Fujimura T, Tsuda H, Osaki A, Saeki T, Inoue S: Estrogen-related receptor $\gamma$ modulates cell proliferation and estrogen signaling in breast cancer. J Steroid Biochem Mol Biol 2011;123:1-7.

45. Girard BJ, Regan Anderson TM, Welch SL, Nicely J, Seewaldt VL, Ostrander JH: Cytoplasmic pelp1 and errgamma protect human mammary epithelial cells from tam-induced cell death. PLoS One 2015;10:e0121206.

46. Lü M, Ding K, Zhang G, Yin M, Yao G, Tian H, Lian J, Liu L, Liang M, Zhu T, Sun F: Microrna-320a sensitizes tamoxifen-resistant breast cancer cells to tamoxifen by targeting arpp-19 and err $\gamma$. Sci Rep 2015;5:8735.

47. Kamarajugadda S, Stemboroski L, Cai Q, Simpson NE, Nayak S, Tan M, Lu J: Glucose oxidation modulates anoikis and tumor metastasis. Mol Cell Biol 2012;32:1893-1907.

48. Lehmann BD, Bauer JA, Chen X, Sanders ME, Chakravarthy AB, Shyr Y, Pietenpol JA: Identification of human triplenegative breast cancer subtypes and preclinical models for selection of targeted therapies. J Clin Invest 2011;121

49. Wang Y, Arvanites AC, Davidow L, Blanchard J, Lam K, Yoo JW, Coy S, Rubin LL, McMahon AP: Selective identification of hedgehog pathway antagonists by direct analysis of smoothened ciliary translocation. ACS Chem Biol 2012;7:1040-1048.

50. Lu Y, Li J, Cheng J, Lubahn DB: Genes targeted by the hedgehog-signaling pathway can be regulated by estrogen related receptor $\beta$. BMC Mol Biol 2015;16:19.

51. Heller E, Hurchla MA, Xiang J, Su X, Chen S, Schneider J, Joeng KS, Vidal M, Goldberg L, Deng H, Hornick MC, Prior JL, Piwnica-Worms D, Long F, Cagan R, Weilbaecher KN: Hedgehog signaling inhibition blocks growth of resistant tumors through effects on tumor microenvironment. Cancer Res 2012;72:897-907.

52. Zhang X, Harrington N, Moraes RC, Wu MF, Hilsenbeck SG, Lewis MT: Cyclopamine inhibition of human breast cancer cell growth independent of smoothened (smo). Breast Cancer Res Treat 2009;115:505-521.

53. Mukherjee S, Frolova N, Sadlonova A, Novak Z, Steg A, Page GP, Welch DR, Lobo-Ruppert SM, Ruppert JM, Johnson MR, Frost AR: Hedgehog signaling and response to cyclopamine differ in epithelial and stromal cells in benign breast and breast cancer. Cancer Biol Ther 2006;5:674-683.

54. Beauchamp EM, Ringer L, Bulut G, Sajwan KP, Hall MD, Lee YC, Peaceman D, Ozdemirli M, Rodriguez O, Macdonald TJ, Albanese C, Toretsky JA, Uren A: Arsenic trioxide inhibits human cancer cell growth and tumor development in mice by blocking hedgehog/gli pathway. J Clin Invest 2011;121:148-160.

55. Turinetto V, Giachino C: Multiple facets of histone variant h2ax: A dna double-strand-break marker with several biological functions. Nucleic Acids Res 2015;43:2489-2498.

56. Solier S, Pommier Y: The nuclear $\gamma$-h2ax apoptotic ring: Implications for cancers and autoimmune diseases. Cell Mol Life Sci 2014;71:2289-2297.

57. Yu S, Wang X, Ng CF, Chen S, Chan FL: Errgamma suppresses cell proliferation and tumor growth of androgensensitive and androgen-insensitive prostate cancer cells and its implication as a therapeutic target for prostate cancer. Cancer Res 2007;67:4904-4914.

58. Lacroix M, Toillon RA, Leclercq G: P53 and breast cancer, an update. Endocr Relat Cancer 2006;13:293-325.

59. Wei Y, Yu L, Bowen J, Gorovsky MA, Allis CD: Phosphorylation of histone h3 is required for proper chromosome condensation and segregation. Cell 1999;97:99-109.

60. Hendzel MJ, Wei Y, Mancini MA, Van Hooser A, Ranalli T, Brinkley BR, Bazett-Jones DP, Allis CD: Mitosis-specific phosphorylation of histone $\mathrm{h} 3$ initiates primarily within pericentromeric heterochromatin during g2 and spreads in an ordered fashion coincident with mitotic chromosome condensation. Chromosoma 1997;106:348-360.

61. Guo XW, Th'ng JP, Swank RA, Anderson HJ, Tudan C, Bradbury EM, Roberge M: Chromosome condensation 
induced by fostriecin does not require p34cdc2 kinase activity and histone h1 hyperphosphorylation, but is associated with enhanced histone h2a and h3 phosphorylation. EMBO J 1995;14:976-985.

62. Healy S, Khan P, He S, Davie JR: Histone h3 phosphorylation, immediate-early gene expression, and the nucleosomal response: A historical perspective. Biochem Cell Biol 2012;90:39-54.

63. Lu C, Shi Y, Wang Z, Song Z, Zhu M, Cai Q, Chen T: Serum starvation induces h2ax phosphorylation to regulate apoptosis via p38 mapk pathway. FEBS Lett 2008;582:2703-2708.

64. Dong Y, Yin S, Song X, Huo Y, Fan L, Ye M, Hu H: Involvement of ros-p38-h2ax axis in novel curcumin analogues-induced apoptosis in breast cancer cells. Mol Carcinog 2016;55:323-334.

65. Dong Y, Xiong M, Duan L, Liu Z, Niu T, Luo Y, Wu X, $\mathrm{Xu} \mathrm{C}, \mathrm{Lu} \mathrm{C}$ : $\mathrm{H} 2 \mathrm{ax}$ phosphorylation regulated by $\mathrm{p} 38$ is involved in bim expression and apoptosis in chronic myelogenous leukemia cells induced by imatinib. Apoptosis 2014;19:1281-1292.

66. Zhong SP, Ma WY, Dong Z: Erks and p38 kinases mediate ultraviolet b-induced phosphorylation of histone h3 at serine 10. J Biol Chem 2000;275:20980-20984.

67. Kanda T, Sullivan KF, Wahl GM: Histone-gfp fusion protein enables sensitive analysis of chromosome dynamics in living mammalian cells. Curr Biol 1998;8:377-385.

68. Sigoillot FD, Huckins JF, Li F, Zhou X, Wong ST, King RW: A time-series method for automated measurement of changes in mitotic and interphase duration from time-lapse movies. PLoS One 2011;6:e25511.

69. Motwani M, Li X, Schwartz GK: Flavopiridol, a cyclindependent kinase inhibitor, prevents spindle inhibitorinduced endoreduplication in human cancer cells. Clin Cancer Res 2000;6:924-932.

70. Woods CM, Zhu J, McQueney PA, Bollag D, Lazarides E: Taxol-induced mitotic block triggers rapid onset of a p53independent apoptotic pathway. Mol Med 1995;1:506-526.

71. Pencheva N, Buss CG, Posada J, Merghoub T, Tavazoie SF: Broad-spectrum therapeutic suppression of metastatic melanoma through nuclear hormone receptor activation. Cell 2014;156:986-1001.

72. Benod C, Villagomez R, Filgueira CS, Hwang PK, Leonard PG, Poncet-Montange G, Rajagopalan S, Fletterick RJ, Gustafsson J, Webb P: The human orphan nuclear receptor tailless (tlx, nr2e1) is druggable. PLoS One 2014;9:e99440.

73. Redon CE, Nakamura AJ, Zhang YW, Ji JJ, Bonner WM, Kinders RJ, Parchment RE, Doroshow JH, Pommier Y: Histone gammah2ax and poly(adp-ribose) as clinical pharmacodynamic biomarkers. Clin Cancer Res 2010;16:4532-4542.

74. Toda K, Naito K, Mase S, Ueno M, Uritani M, Yamamoto A, Ushimaru T: Apc/c-cdh1-dependent anaphase and telophase progression during mitotic slippage. Cell Div 2012;7:4.
75. Bombail V, Collins F, Brown P, Saunders PT: Modulation of er alpha transcriptional activity by the orphan nuclear receptor err beta and evidence for differential effects of long- and short-form splice variants. Mol Cell Endocrinol 2010;314:53-61.

76. Zyss D, Montcourrier P, Vidal B, Anguille C, Mérezègue F, Sahuquet A, Mangeat PH, Coopman PJ: The syk tyrosine kinase localizes to the centrosomes and negatively affects mitotic progression. Cancer Res 2005;65:10872-10880.

77. Wang CY, Lai PY, Chen TY, Chung BC: Nr5a1 prevents centriole splitting by inhibiting centrosomal dna-pk activation and $\beta$-catenin accumulation. Cell Commun Signal 2014;12:55.

78. Wang CY, Chen WY, Lai PY, Chung BC: Distinct functions of steroidogenic factor-1 (nr5a1) in the nucleus and the centrosome. Mol Cell Endocrinol 2013;371:148-153.

79. Wang CY, Kao YH, Lai PY, Chen WY, Chung BC: Steroidogenic factor 1 (nr5a1) maintains centrosome homeostasis in steroidogenic cells by restricting centrosomal dna-dependent protein kinase activation. Mol Cell Biol 2013;33:476-484.

80. Lingle WL, Barrett SL, Negron VC, D'Assoro AB, Boeneman K, Liu W, Whitehead CM, Reynolds C, Salisbury JL: Centrosome amplification drives chromosomal instability in breast tumor development. Proc Natl Acad Sci U S A 2002;99:1978-1983.

81. Lee MY, Marina M, King JL, Saavedra HI: Differential expression of centrosome regulators in her2+ breast cancer cells versus non-tumorigenic mcf10a cells. Cell Div 2014;9:3.

82. Godinho SA, Picone R, Burute M, Dagher R, Su Y, Leung CT, Polyak K, Brugge JS, Théry M, Pellman D: Oncogenelike induction of cellular invasion from centrosome amplification. Nature 2014;510:167-171.

83. Rathinasamy K, Jindal B, Asthana J, Singh P, Balaji PV, Panda D: Griseofulvin stabilizes microtubule dynamics, activates p53 and inhibits the proliferation of mef-7 cells synergistically with vinblastine. BMC Cancer 2010;10:213.

84. Li Y, Lu W, Chen D, Boohaker RJ, Zhai L, Padmalayam I, Wennerberg K, Xu B, Zhang W: Kifc1 is a novel potential therapeutic target for breast cancer. Cancer Biol Ther 2015:1-7.

85. Zasadil LM, Andersen KA, Yeum D, Rocque GB, Wilke LG, Tevaarwerk AJ, Raines RT, Burkard ME, Weaver BA: Cytotoxicity of paclitaxel in breast cancer is due to chromosome missegregation on multipolar spindles. Sci Transl Med 2014;6:229ra243.

86. Kwon M, Godinho SA, Chandhok NS, Ganem NJ, Azioune A, Thery M, Pellman D: Mechanisms to suppress multipolar divisions in cancer cells with extra centrosomes. Genes Dev 2008;22:2189-2203.

87. Pannu V, Mittal K, Cantuaria G, Reid MD, Li X, Donthamsetty S, McBride M, Klimov S, Osan R, Gupta 
MV, Rida PC, Aneja R: Rampant centrosome amplification underlies more aggressive disease course of triple negative breast cancers. Oncotarget 2015;6:10487-10497. doi:10.18632/oncotarget.3402.

88. Györffy B, Lanczky A, Eklund AC, Denkert C, Budczies J, Li Q, Szallasi Z: An online survival analysis tool to rapidly assess the effect of 22,277 genes on breast cancer prognosis using microarray data of 1,809 patients. Breast Cancer Res Treat 2010;123:725-731.

89. Goldhirsch A, Winer EP, Coates AS, Gelber RD, PiccartGebhart M, Thürlimann B, Senn HJ, members P: Personalizing the treatment of women with early breast cancer: Highlights of the st gallen international expert consensus on the primary therapy of early breast cancer 2013. Ann Oncol 2013;24:2206-2223.

90. Garattini E, Bolis M, Gianni’ M, Paroni G, Fratelli M, Terao M: Lipid-sensors, enigmatic-orphan and orphan nuclear receptors as therapeutic targets in breast-cancer. Oncotarget 2016; doi: 10.18632/oncotarget.7410.
91. Cowley SM, Parker MG: A comparison of transcriptional activation by er alpha and er beta. JSteroid BiochemMolBiol 1999;69:165-175.

92. Hong H, Yang L, Stallcup MR: Hormone-independent transcriptional activation and coactivator binding by novel orphan nuclear receptor err3 1. JBiol Chem 1999;274:22618-22626.

93. Suzuki K, Bose P, Leong-Quong RY, Fujita DJ, Riabowol K: Reap: A two minute cell fractionation method. BMC Res Notes 2010;3:294.

94. Dixon M, Woodrick J, Gupta S, Karmahapatra SK, Devito S, Vasudevan S, Dakshanamurthy S, Adhikari S, Yenugonda VM, Roy R: Naturally occurring polyphenol, morin hydrate, inhibits enzymatic activity of n-methylpurine dna glycosylase, a dna repair enzyme with various roles in human disease. Bioorg Med Chem 2015;23:1102-1111.

95. Adhikari S, Uren A, Roy R: Excised damaged base determines the turnover of human n-methylpurine-dna glycosylase. DNA Repair (Amst) 2009;8:1201-1206. 